\title{
Removal of Basic Brown 16 from Aqueous Solution Using Durian Shell Adsorbent, Optimisation and Techno-Economic Analysis
}

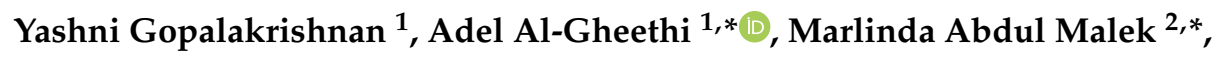 \\ Mawar Marisa Azlan ${ }^{1}$, Mohammed Al-Sahari ${ }^{1}{ }^{\mathbb{C}}$, Radin Maya Saphira Radin Mohamed ${ }^{1, *}$, \\ Sadeq Alkhadher ${ }^{1}$ and Efaq Noman ${ }^{3,4}{ }^{1}$ \\ 1 Micropollutant Research Centre (MPRC), Faculty of Civil Engineering \& Built Environment, \\ Universiti Tun Hussein Onn Malaysia, Parit Raja 86400, Batu Pahat, Johor, Malaysia; \\ yashni_g@yahoo.com (Y.G.); mawarmarisa@yahoo.com (M.M.A.); mohammedalsahari@gmail.com (M.A.-S.); \\ sadeqalkhather@yahoo.com (S.A.) \\ 2 Institute of Sustainable Energy, Universiti Tenaga Nasional, Selangor 43000, Malaysia \\ 3 Department of Applied Microbiology, Faculty of Applied Science, Taiz University, Taiz City 00967, Yemen; \\ eanm1984@gmail.com \\ 4 Faculty of Applied Sciences and Technology, University Tun Hussein Onn Malaysia (UTHM), \\ Pagoh Higher Education Hub, KM 1, Jalan Panchor, Panchor 84000, Johor, Malaysia \\ * Correspondence: adel@uthm.edu.my (A.A.-G.); Marlinda@uniten.edu.my (M.A.M.); maya@uthm.edu.my \\ (R.M.S.R.M.); Tel.: +60-01-111-098-362 (A.A.-G.); +6019-33-22-775 (M.A.M.); Fax: +603-8921-2116 (M.A.M.)
}

Received: 2 September 2020; Accepted: 27 September 2020; Published: 27 October 2020 updates

\begin{abstract}
Azo dyes including C. I. Basic Brown 16 (BB16) are one of the coloured organic compounds that have adverse effects on human health and the environment. The current work aims to optimise the adsorption of C.I BB16 in aqueous solution using durian (Durio zibethinus murray) shell as a low-cost green adsorbent. Durian shell was characterised by Fourier transform infrared spectroscopy (FTIR) and scanning electron microscopy (SEM). The adsorption process was optimised with response surface methodology (RSM) based on pH (4-8), time (30-240 $\mathrm{min})$, durian shell dosage (0.1-1.0 g/L) and initial concentration of C.I BB16 (10-20 ppm). The removal efficiency was determined based on the reduction of chemical oxygen demand (COD) and the decolourisation of C.I BB16. The techno-economic analysis was described in the current work to know the economic feasibility of durian shells as an adsorbent. The SEM images showed that durian shell adsorbent has a smooth surface with no pores. FTIR spectra confirmed the presence of $-\mathrm{C}-\mathrm{O},=\mathrm{C}-\mathrm{H}, \mathrm{C}=\mathrm{C},-\mathrm{C}-\mathrm{O}-\mathrm{C}$ and $\mathrm{O}-\mathrm{H}$ bonds in durian shell. Maximum decolourisation (77.6\%) and COD removal (80.6\%) for C.I BB16 was achieved with the interaction between $\mathrm{pH}$, time and adsorbent dose and initial concentration of C.I BB16. The optimal operating factors for adsorption of C.I BB16 recorded at $\mathrm{pH} 8$, time (30 $\mathrm{min})$, durian shell dosage $(1 \mathrm{~g} / \mathrm{L})$ and $15 \mathrm{mg} / \mathrm{L}$ of C.I BB16 concentrations were 77.61 vs. 74.26 (\%) of C.I BB16 removal and 80.60 vs. $78.72(\%)$ of COD removal with an $\mathrm{R}^{2}$ coefficient of 0.94 at $p<0.05$. The specific cost of durian shell coagulant production is USD 172.71 per ton which is lower than the market price of honeydew peels-activated carbon (HDP-AC) (USD 261.81) and the commercial market price of activated carbon which is USD 1000.00/tons. These findings indicated that the durian adsorbent provides alternative methods for treating hair dye wastewater. These findings indicated that durian shells have a high potential for the adsorption of C.I BB16 in aqueous solution.
\end{abstract}

Keywords: Basic Brown 16; adsorption; durian shell; mechanism; techno-economic analysis 


\section{Introduction}

Azo dyes are coloured organic compounds bearing the functional group $\mathrm{R}-\mathrm{N}=\mathrm{N}-\mathrm{R}^{\prime}$, in which $\mathrm{R}$ and $\mathrm{R}^{\prime}$ are aryl or heteroaryl. More than 0.7 million tons of these compounds are produced every year from which $10-15 \%$ enters into the environment through industrial wastewater, especially textile industries [1]. The improper disposal of these wastewaters is the main problem of environmental pollution because of its high toxicity and stability to withstand degradation even under extreme circumstances [2]. The main concerns related to the presence of azo dyes in water ecosystems are its effect on water transparency, photosynthetic activity reduction and the harmful consequences on aquatic flora and fauna. Moreover, most of the azo dyes have been documented to be mutagens or carcinogens to human beings [3]. C. I. BB16 is one of the most applicable dyes in the textile and biological dyeing industries. It contains $(-\mathrm{N}=\mathrm{N}-)$ as chromophore connected to aromatic systems with lateral groups, including $\mathrm{CH}_{3}$, which can be very harmful and resistant to conventional treatment processes. Although C.I BB16 has caused health hazards because of which it has been prohibited in many areas, it is still widely practised in several countries [4].

Several treatment technologies for removing azo dyes from industrial wastewater have been used such as coagulation-flocculation [5], chemical and electrochemical oxidation [6], ozonation [7], ion exchange [2] and anaerobic-aerobic system [8]. However, most of the azo dyes are still persistent in the treated wastewater because of their high stability. Therefore, the removal of azo dyes required an advanced removal technology such as adsorption which is one of the most favourable processes in comparison to other practices because of its simplicity, practicality, productivity and inexpensiveness [9]. Adsorption is also known as physical attachment or binding of ions and molecules onto the surface of other molecular substances [10]. The exploration for new adsorbents has been concentrated on biomaterials because of their high availability, eco-friendliness, economic feasibility and source i.e., from renewable materials. These resources are locally and easily accessible in considerable quantities in the agroindustry. Thus, they are typically inexpensive and have little or no economic significance. For instance, these resources are wastes with no industrial or agricultural use, with their accumulation being problematic in many cases [11]. The adsorbents comprise proteins, polysaccharides, cellulose and lignin, which contain various functional groups such as phenolic and amino groups that are accountable for pollutant adsorption. Among several plants, pineapple plant stem [12], leaves of Prunus Dulcis [13], tomato waste and apple juice residue [14], grape peel [15], Thapsia transtagana stems [16], mushroom [17] have been reported to produce biocompatible adsorbents.

In this study, Durio Zibethinus Murray (durian) shell was utilised for the adsorption of C.I BB16 because of its richness in proteins, polysaccharides, cellulose and lignin that contain various functional groups such as phosphate, carboxyl, sulphate, phenolic and amino groups that are accountable for azo dyes adsorption [18]. Moreover, the durian shell contains high fibre content that contributes to the adsorption process [19]. Durian peels are broadly obtainable as a waste from the durian processing business at a cheaper rate in comparison to other natural supplies. This is because only one-third of durian is digestible (20-30\% flesh), whereas the shell and the seed (55-66\%) are generally disposed of [20]. The productivity of durian in Malaysia alone was 3800 metric tons in the year 2016 and 22,000 metric tons in the year 2020. With every 10 tons, more than 7 tons of durian shells are produced [21]. Although durian shell as adsorbent was investigated by previous researchers [21,22], no comprehensive study has been conducted on the optimisation of adsorption of C.I BB16 by using a response surface methodology (RSM) and this emphasises the novelty of the current work.

Figure 1 presents the bibliometric analysis of 43 papers published on the durian shell according to the Scopus database using specific keywords such as "durian" AND "adsorption". It was noted that the durian shell was used as an adsorbent for removing methylene blue, basic dyes, brilliant green, basic green four dye, crystal violet, gentian violate, acid green 25 as well as heavy metals such as chromium, lead, zinc from different wastewater sources. The main factors affecting the adsorption process included $\mathrm{pH}$, time, the concentration of pollutants, moisture and particle size of the durian 
shell powder. The durian shells have been subjected to acid treatment to prepare charcoal, biochar and carbon active which are the most common adsorbents.

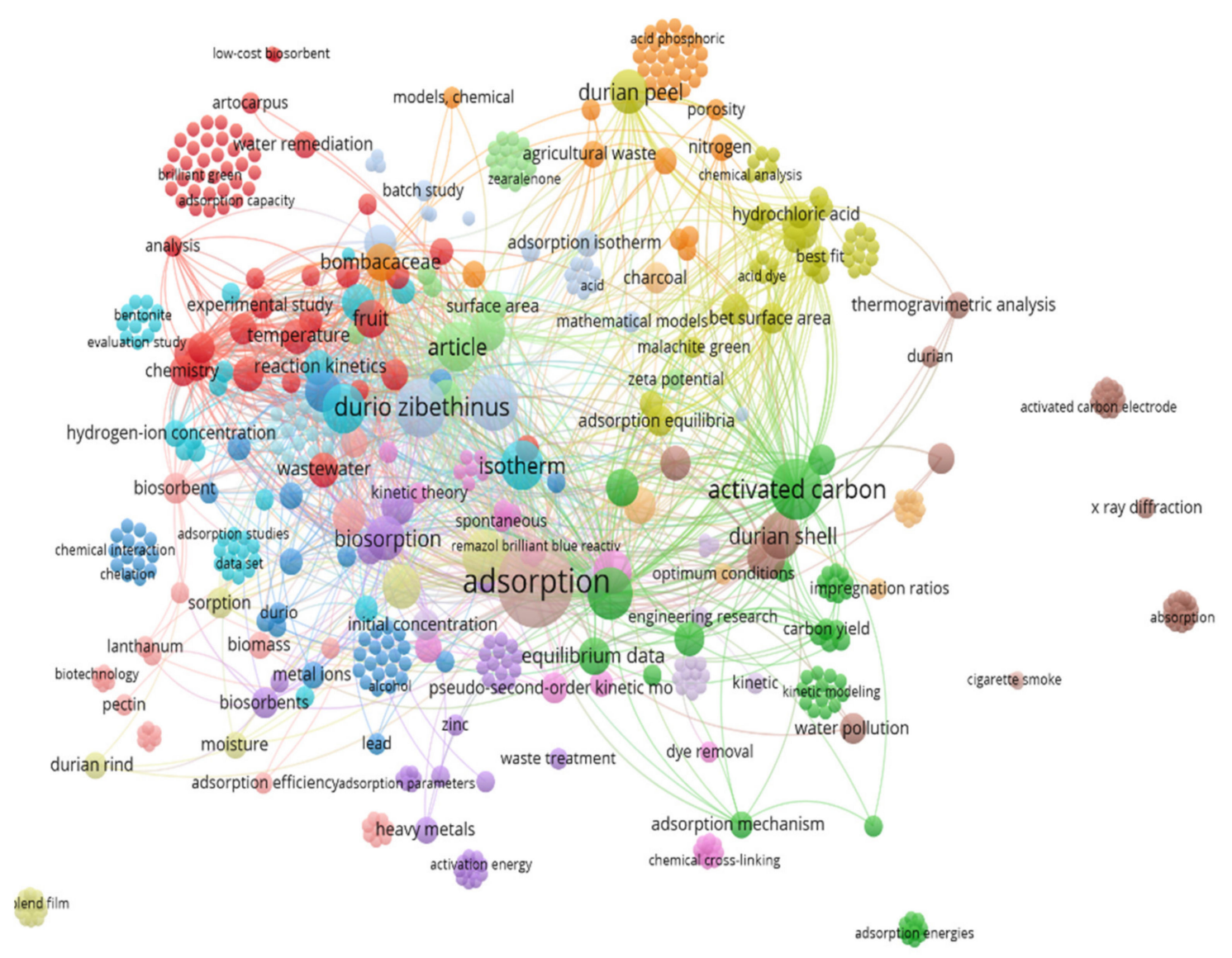

Figure 1. Bibliometric analysis for 43 paper published on the durian shell according to the Scopus database using specific keywords included "durian" AND "adsorption".

The factors affecting adsorption need to be optimised to reinforce the process of adsorption. Response surface methodology (RSM) is a tool that uses the mathematical and statistical approach to develop, optimise and enhance products and industrial processes. The main aim of RSM is to lessen the number of experimental runs and attain maximum data output. It allows changing numerous variables at the same time to plan fewer number of experiments needed to optimise the desired process [23]. RSM can be used to study the effects of independent variables, multiple factors and their interaction effects [24]. The effects of two or more variables are determined by factorial design. Meanwhile, central composite design (CCD) with RSM is used for the optimisation process. Besides, the application of CCD prevents deceiving conclusions and grant conclusions that are appropriate for several experimental conditions. Only one study has been optimised for the durian seed prepared as activated carbon for removing C.I methylene blue [25]. However, RSM is not used as a modelling and optimisation tool for the adsorption of C. I BB16. Moreover, techno-economic analysis is used for evaluating the potential of agriculture wastes as an alternative adsorbent for the commercial activated carbon (AC). No study has investigated the final price of the durian shell compared with that of commercial products in the market. The current price of 1 ton AC from coal ranges from USD 1190 to 16343/tons AC [26]. Therefore, the current study aims to optimise the factors affecting the adsorption of C.I BB16 by durian shell as an adsorbent by RSM. Moreover, techno-economic analysis for the preparation and application of durian shell adsorbent was conducted and compared with that of commercial AC products. 


\section{Materials and Methods}

\subsection{Preparation of Durian Shell as an Adsorbent}

The durian shells were gathered locally from the neighbourhood shops. The durian shell was rinsed two to three times by water for the removal of dirt and impurities followed by open-air drying for $48 \mathrm{~h}$. Thereafter, it was oven-dried at $150{ }^{\circ} \mathrm{C}$ for $24 \mathrm{~h}$. The dried durian shell was then ground and sieved to the particle size $<150 \mu \mathrm{m}$. The ground durian shell was kept in the airtight plastic container for the adsorption studies [22]. It was noted that $1 \mathrm{~kg}$ of durian shell generates $500 \mathrm{~g}$ of the powder adsorbent with particle size $<150 \mu \mathrm{m}$.

\subsection{Characterisation of Adsorbent}

\subsubsection{Field Emission Scanning Electron Microscope (FESEM)}

The surface texture and morphology of the durian shell was analysed by field emission scanning electron microscopy (FESEM; Ion Company, New York, NY, USA). The sample was prepared by mixing two drops of $100 \%$ ethanol with $0.1 \mathrm{~g}$ durian shell on clean silicon wafers and then dried at $50{ }^{\circ} \mathrm{C}$ for 2 min to eliminate the solvent, coated with gold using the sputtering technique, fractured and observed at a beam energy of $20 \mathrm{kV}$.

\subsubsection{Fourier Transform Infrared (FTIR)}

The functional groups in the durian shell were identified by Fourier transform infrared (FTIR) spectroscopy using Nicolet iS50 (Thermo Scientific, Waltham, MA, USA) with a scanning range of 400-4000 $\mathrm{cm}^{-1}$ using attenuated total reflection (ATR) technique. First, the crystal plate (sample holder) was cleaned with acetone. The durian shell sample $(5 \mathrm{mg})$ was placed directly on the crystal plate and then pressed using the metallic pressing device and scanned to get the IR spectrum [27].

\subsection{Preparation of C.I BB16 in Aqueous Solution}

C.I BB16 was supplied by Sigma-Aldrich (M) Sdn Bhd, Malaysia, and used as received without further purification. A stock solution of $1000 \mathrm{mg} / \mathrm{L}$ was prepared by dissolving the appropriate amount (1000 mg) of C.I BB16 in a litre of deionised water. The working solution was prepared by diluting the stock solution with deionised water to give the appropriate concentration of the working solutions [28].

\subsection{Experimental Set-up}

The experimental set-up in this study includes the preparation of durian shell and C.I BB16 solution, independent factors and optimisation process. Factorial complete randomised design (CRD) $(3 \times 3 \times 3)$ in triplicate was executed to investigate the independent factors that affect the adsorption of C.I BB16. Four independent factors that are $\mathrm{pH}(4-8)$, time (30-240 min), durian shell dosage (0.1-1.0 g) and initial C.I BB16 concentration (10-20 ppm) were investigated. The range for each independent factor was chosen based on previous investigations $[29,30]$.

\subsubsection{Adsorption of C.I BB16}

The adsorption of C.I BB16 experiments were performed using a $250 \mathrm{~mL}$ Erlenmeyer conical flask that holds $100 \mathrm{~mL}$ of an aqueous solution of C.I BB16. To ascertain the $\mathrm{pH}$ condition, the $\mathrm{pH}$ was modified deliberately for the solution, ranging between 4 and 8 . These were conducted by using $0.1 \mathrm{M}$ sodium hydroxide $(\mathrm{NaOH})$ and 0.1 hydrochloric acid $(\mathrm{HCI})$ to acquire the desired $\mathrm{pH}$ value [31]. The mixture was stirred using the orbital shaker at $150 \mathrm{rpm}$ and the contact time was specified between $30 \mathrm{~min}$ and $4 \mathrm{~h}$. Treated C.I BB16 samples were filtered using the membrane filter $(0.2 \mu \mathrm{m})$ [16]. The efficiency of the durian shell in the adsorption of C.I BB16 was investigated by determining the absorbance of C.I BB16 sample before and after each experimental run using UV-Vis spectrophotometer 
(DR6000) at 661 and $620 \mathrm{~nm}$. The adsorption of C.I BB16 efficiency was determined by calculating the decolourisation according to Equation (1) [32]

$$
\text { Decolorisation }(\%)=\frac{A_{0}-A}{A_{0}}
$$

where $A_{0}$ is the initial absorbance of C.I BB16 in samples before the adsorption and $A$ is the absorbance of C.I BB16 after the adsorption-moreover, the mineralisation of C.I BB16 was confirmed by COD analysis, according to Gonçalves et al., [11]. COD reduction was calculated using Equation (2)

$$
\operatorname{COD}(\%)=\frac{C_{0}-C_{f}}{C_{0}}
$$

where $C_{0}$ is the initial COD concentration $(\mathrm{mg} / \mathrm{L})$ and $C_{f}$ is the final COD concentration $(\mathrm{mg} / \mathrm{L})$ after the adsorption.

\subsubsection{Optimisation of Adsorption of C.I BB16}

The experimental set-up of the current work consists of C.I BB16 solutions and durian shell adsorbent as well as pseudo-first and second-order kinetic model for adsorption process using response surface methodology $(\mathrm{RSM})$. The factorial complete randomised design $(\mathrm{CRD})(4 \times 2)$ in triplicates was used to study the optimal factors affecting the adsorption process with four (4) independent factors (( $\mathrm{pH} 4-8), x_{2}$ (time, 30-240 min), $x_{3}$ (adsorbent dosage $(0.1-1 \mathrm{~g} / \mathrm{L}), x_{4}$ (initial concentration of C.I BB16) (10-20 mg/L) and two dependent variables $y_{1}$ (decolourisation of C.I BB16) $(\%), y_{2}$ (COD removal) (\%). The independent factors were selected and used for designing the experimental runs using Design Expert 6.0.10, central composite design (CCD) (Stat-Ease Inc., Minneapolis, MN, USA) software that suggested 25 experimental runs. The experimental runs (one run recommended) were carried out to authenticate the efficiency of the results of the evaluated elements. Four independent variables including $\mathrm{pH}$, time, durian shell dosage and initial concentration of C.I BB16 were optimised for adsorption of C.I BB16. The optimisation experiments were also operated in three replicates to enhance the estimated data accuracy by inferring that no bias and systematic error exist. Moreover, the variables' ranges (high and low) in this study are depicted as (low, medium and high, being coded as $-1,0$ and +1 ). The efficiency of adsorption of C.I BB16 was verified by the percentage of the removal (y) which was denoted as the responses of the parameters of the experimental design. The parameters examined for adsorption of C.I BB16 were decolourisation (\%) $\left(y_{1}\right)$ and COD removal (\%) $\left(y_{2}\right)$ and the working variables were $x_{1}, x_{2}, x_{3}$ and $x_{4}$. The quadratic model used to get the optimisation of the responses as a function of the independent process variables is as follows:

$$
y=\beta 0+\sum_{i=1}^{k} \beta_{i} x_{i}+\sum_{i=1}^{k} \beta_{i i} x_{i}{ }^{2}+\sum_{i=1}^{n} \sum_{i<j}^{n} \beta_{i j} x_{i} x_{j}
$$

where $y$ is the expected response for the adsorption, while $\beta 0, \beta_{i}, \beta_{i i}$ and $\beta_{i j}$ are the linear model coefficients, $x_{i}$ is the coded independent factors, and $x_{i}$ is the independent factors in a coded form, while $k$ represents independent variable numbers.

The relationship between the experimental data and the coded variable is represented as:

$$
x_{i}=\varepsilon_{i} \frac{[\mathrm{HL}+\mathrm{LL}] / 2}{[\mathrm{HL}-\mathrm{LL}] / 2}
$$

where $x_{i}$ represents the coded variable, $\varepsilon_{i}$ is the experimental laboratory data, HL and LL represent the maximum and minimum values of the independent factors respectively. 


\subsection{Techno-Economic Analysis for Hair Dye Greywater Treatment Using Durian Shell Adsorbent}

The annual time for the fill operation including preparation and application is $5760 \mathrm{~h} / \mathrm{year}$ (which is equivalent to 240 operating days). The TCI for a proposed preparation and application processes includes WCC and FCE (Equation (5)) [33,34].

$$
T C I=W C C+F C E
$$

where TCI is the total capital investment, WCC is the working capital cost and FCE is the fixed capital estimation.

The annual operation cost $(A O C)$ for the preparation of durian shell as adsorbent and then the application of the adsorbent in the hair dye greywater and the costs of raw materials $\left(C_{R M}\right)$, waste generated from the preparation process $\left(C_{W G}\right)$, utilities $\left(C_{U}\right)$ and extra cost $\left(C_{E}\right)$ were calculated on an annual basis according to Equation (6).

$$
\left.A O C=C_{R M}+C_{W G}+C_{U}+C_{E}\right)
$$

According to the mathematical model designed by the specific cost of durian shell adsorbent production $C_{Z}(\mathrm{~kg} / \mathrm{USD})$ is calculated based on the annual costs of capital $C_{C}$, utilities $\operatorname{cost} C_{U}$, raw material $\operatorname{cost} C_{R M}$ and extra $\operatorname{cost} C_{E}$ divided by the annual durian shell adsorbent production (Equation (7)) [35].

$$
C_{Z}=\frac{\left(C_{C}+C_{U}+C_{R M}+C_{E}\right)}{E_{P}}
$$

\subsection{Statistical Analysis}

The significant role of the independent factors as well as the interactions between these factors was analysed using ANOVA $(p<0.05)$. The contribution of independent factors in the adsorption as a function for the quadratic model was identified by the adjusted coefficient of determination ( $R^{2}$ adj). The relationship between the independent factors and their effects on the adsorption was represented in a three-dimensional graphical representation, which is RSM.

\section{Results and Discussion}

\subsection{Characteristics of Durian Adsorbent}

The surface morphology of the durian shell before and after the adsorption process is presented in Figure 2. It was noted that the adsorbent surface having a smooth surface with no pores might be due to the existence of pectin and lignin. These findings are inconsistent with those reported by Lazim et al. [22]. In contrast, the durian shell after the adsorption process have rough surface morphology with dye residues.

The FT-IR spectrum of the durian shell is shown in Figure 3. The FTIR spectra showed a broad peak at $3413.86 \mathrm{~cm}^{-1}$ which specifies the existence of phenol group of lignin and cellulose. The peaks at 1623.92 are assigned as the $\mathrm{C}=\mathrm{C}$ aromatic bond or amide areas that are characteristics of proteins and enzymes. The spectrum exhibited at 1437.20 is classified as the C-O stretching vibrations of carboxylic acids (-COOH) and the spectrum at $1054.42 \mathrm{~cm}^{-1}$ corresponds to the asymmetric stretch of $\mathrm{C}-\mathrm{N}$ bonds from substituted amines [36]. The small band at $616.98 \mathrm{~cm}^{-1}$ owing to the $\mathrm{C}-\mathrm{Cl}$ stretching of alkyl halides [37]. Similarly, Tham et al. [38] observed $3334 \mathrm{~cm}^{-1}$ which is related to the hydroxyl $(\mathrm{O}-\mathrm{H})$ group such as alcohol and phenols. They also observed peaks at $1024 \mathrm{~cm}^{-1}$ and $1420 \mathrm{~cm}^{-1}$ respectively representing coupled $\mathrm{C}-\mathrm{O}$ stretching and amides functional groups of primary amides and aliphatic amides respectively. 


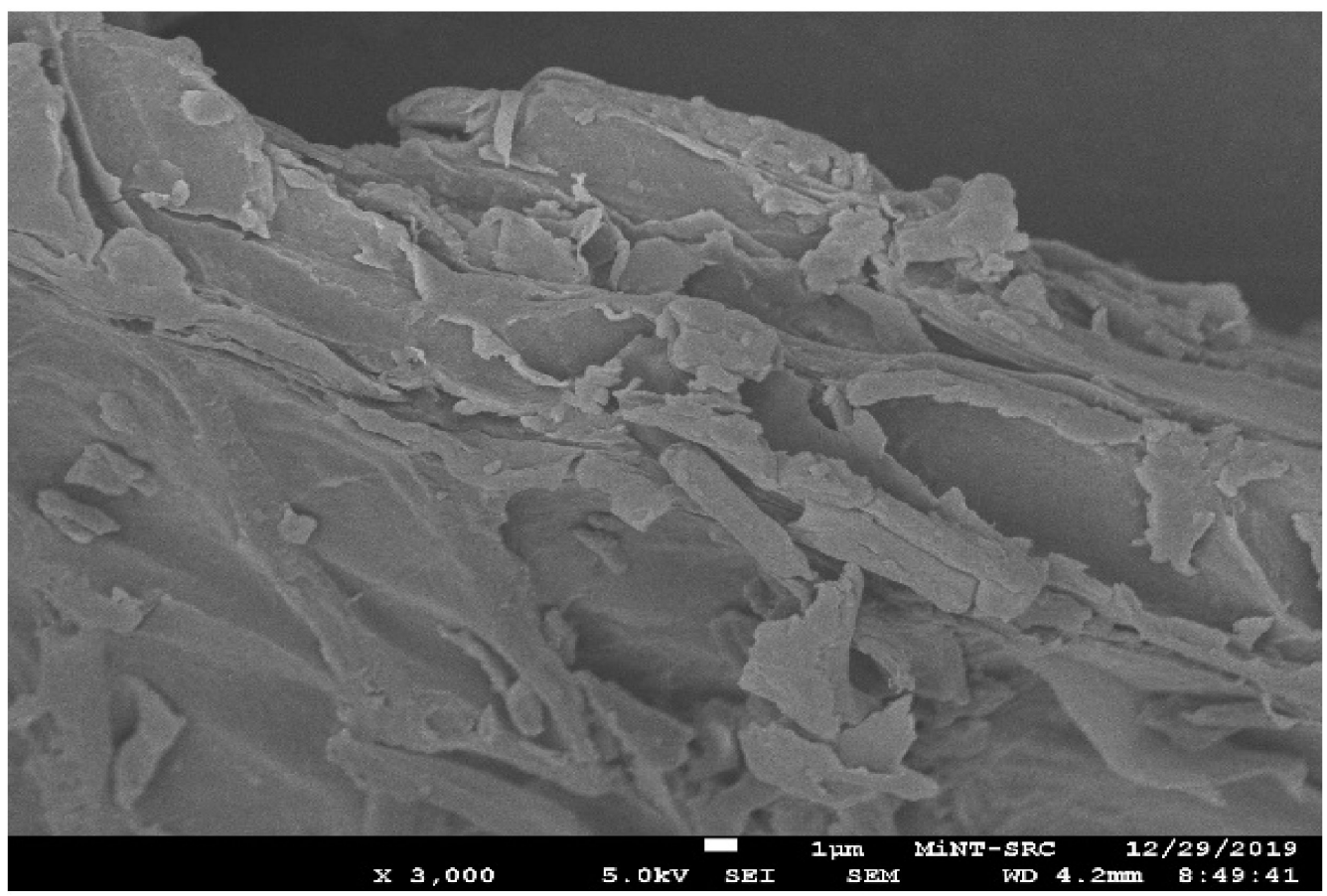

(A)

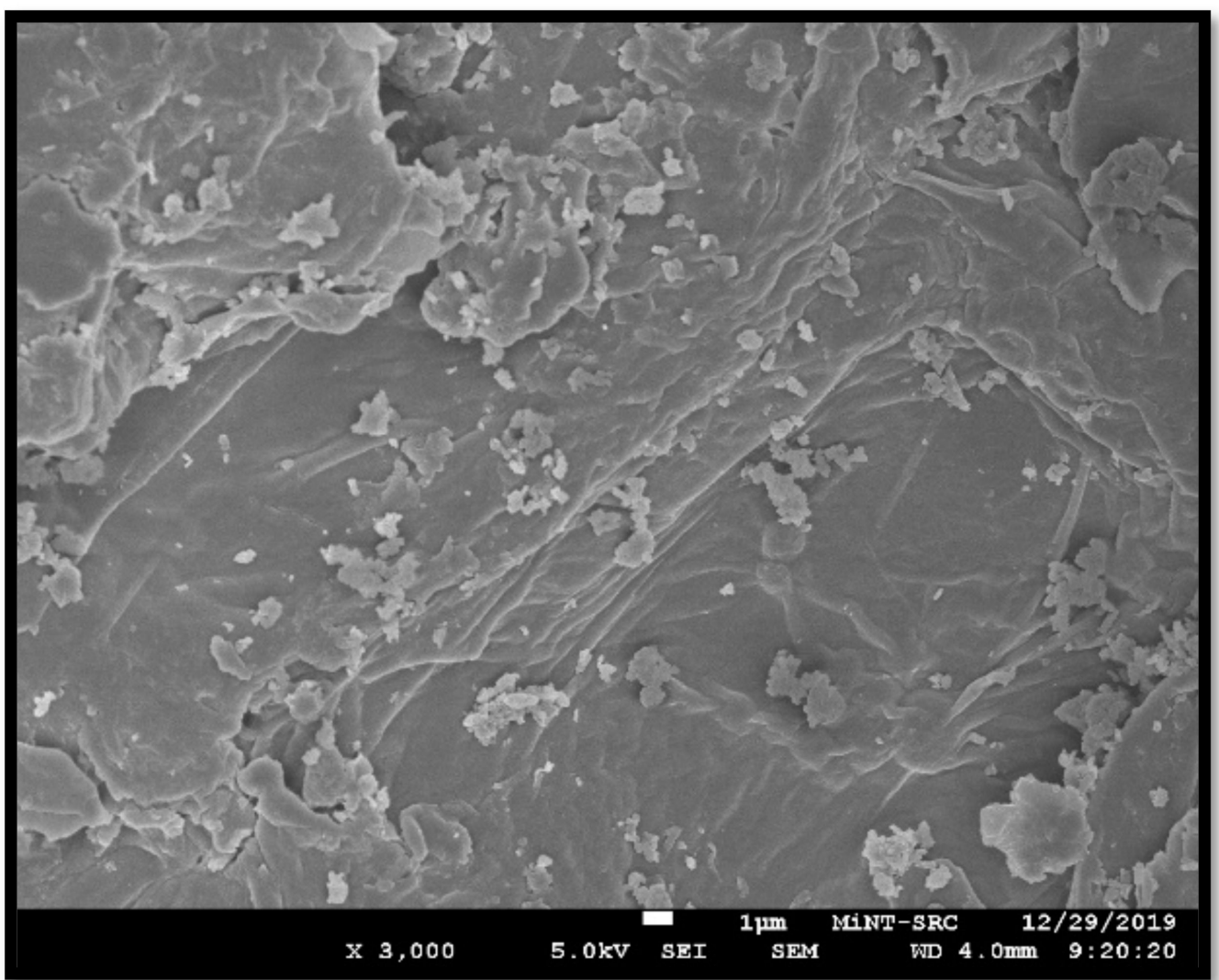

(B)

Figure 2. Surface morphology of durian shell adsorbent using FESEM; (A) before (B) after. 


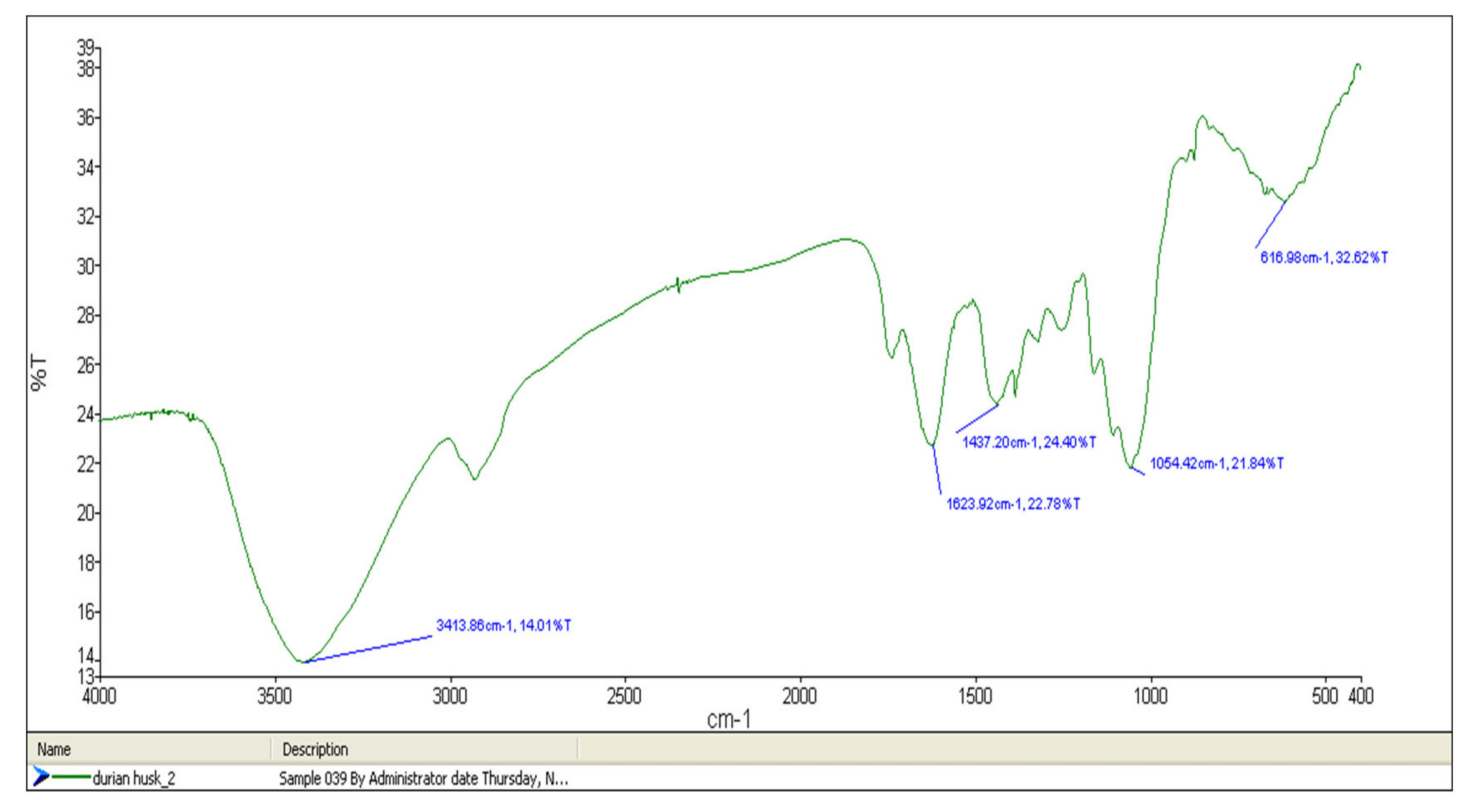

Figure 3. FTIR analysis of durian shell.

\subsection{Optimisation of Adsorption of C.I BB16}

The parameter for optimisation of the adsorption of C.I BB16 using durian shell as adsorbent was performed in the current study by Design-Expert software-the maximum decolourisation of C.I BB16 $80.7 \%$ recorded at $\mathrm{pH} 4,30 \mathrm{~min}, 0.1 \mathrm{~g} / \mathrm{L}$ of the adsorbent dosage and $10 \mathrm{mg} / \mathrm{L}$ of the initial concentration of C.I BB16. In contrast, the maximum reduction of COD was $86.2 \%$ at $\mathrm{pH} 6$, after $30 \mathrm{~min}$, with $1 \mathrm{~g} / \mathrm{L}$ of adsorbent dosage and $10 \mathrm{mg} / \mathrm{L}$ of C.I BB16 initial concentrations (Table 1).

Table 1. Central composite design arrangement and responses for adsorption of C.I BB16 in aqueous solution.

\begin{tabular}{ccccccc}
\hline Run & $x_{1}$ & $x_{2}$ & $x_{3}$ & $x_{4}$ & $y_{1}$ & $y_{2}$ \\
\hline 1 & 4.00 & 30.00 & 0.10 & 10.00 & 80.65 & 57.52 \\
2 & 8.00 & 30.00 & 0.10 & 10.00 & 77.36 & 63.82 \\
3 & 8.00 & 30.00 & 1.00 & 15.00 & 72.81 & 78.09 \\
4 & 8.00 & 30.00 & 0.10 & 20.00 & 72.01 & 55.14 \\
5 & 8.00 & 30.00 & 0.10 & 20.00 & 77.24 & 59.79 \\
6 & 4.00 & 30.00 & 1.00 & 20.00 & 82.07 & 62.06 \\
7 & 4.00 & 30.00 & 0.10 & 10.00 & 76 & 78.22 \\
8 & 6.00 & 30.00 & 1.00 & 10.00 & 71.04 & 86.18 \\
9 & 6.00 & 30.00 & 0.55 & 15.00 & 72.82 & 79.54 \\
10 & 8.00 & 30.00 & 1.00 & 15.00 & 77.61 & 80.6 \\
11 & 4.00 & 135.00 & 0.55 & 15.00 & 72.78 & 30.11 \\
12 & 4.00 & 135.00 & 1.00 & 10.00 & 70.26 & 68.33 \\
13 & 8.00 & 135.00 & 1.00 & 20.00 & 72.07 & 53.08 \\
14 & 8.00 & 135.00 & 1.00 & 20.00 & 72.54 & 52.02 \\
15 & 6.00 & 135.00 & 0.10 & 15.00 & 40.03 & 18.08 \\
16 & 4.00 & 135.00 & 0.10 & 20.00 & 50 & 10.64 \\
17 & 8.00 & 135.00 & 0.55 & 15.00 & 56.28 & 29.53 \\
18 & 6.00 & 135.00 & 1.00 & 15.00 & 57.64 & 58.85 \\
19 & 8.00 & 240.00 & 0.10 & 10.00 & 46 & 28.54 \\
20 & 8.00 & 240.00 & 0.10 & 20.00 & 38.82 & 26.23 \\
21 & 8.00 & 240.00 & 1.00 & 10.00 & 51.22 & 56.74 \\
22 & 4.00 & 240.00 & 0.10 & 10.00 & 40.61 & 24.88 \\
23 & 4.00 & 240.00 & 1.00 & 20.00 & 69.34 & 48.65 \\
24 & 8.00 & 240.00 & 1.00 & 10.00 & 62.86 & 67.94 \\
25 & 6.00 & 240.00 & 0.55 & 15.00 & 52.05 & 32.46 \\
\hline
\end{tabular}

$x_{1}(\mathrm{pH}), x_{2}$ (time), $x_{3}$ (adsorbent dosage (g/L), $x_{4}$ (initial concentration of C.I BB16) (mg/L), $y_{1}$ (decolourisation of C.I BB16) (\%), $y_{2}$ (COD removal) (\%). 
In comparison Lazim et al. [22] revealed that a durian peel had removed $69.60 \%$ of bisphenol with an adsorption capacity of $4.20 \mathrm{mg} / \mathrm{g}$ for $24 \mathrm{~h}$. These differences would be related to the types of pollutants treated in their investigations. Lazim et al. [22] studied the bisphenol, while in this study, C.I BB16 dye was treated. Moreover, they treated the durian peel with sulfuric acid before the adsorption bisphenol. Besides, Abd Latib et al. [39] revealed that $99 \%$ of methylene blue had been removed using durian shell activated carbon at the conditions $0.60 \mathrm{M} \mathrm{H}_{2} \mathrm{O}_{2}$ at $700{ }^{\circ} \mathrm{C}$ for $30 \mathrm{~min}$. The findings in the present study indicated that the investigated factors play an important role in the adsorption and mineralisation rate of C.I BB16. Decolourisation and mineralisation in the adsorption process are affected by $\mathrm{pH}$, time, durian shell dosage and initial C.I BB16 concentration. In this study, the effect of $\mathrm{pH}$ on the adsorption and mineralisation of C.I BB16 was studied at different $\mathrm{pH}$ values ranging from 4.0 to 8.0. It is well accepted that the $\mathrm{pH}$ of the solution plays a vital part in the adsorption process, which influences the surface charge of the adsorbent and the degree of ionisation and specification of the adsorbate. Generally, it can be deduced that adsorption of C.I BB16 dye by durian shell adsorbent was low at low $\mathrm{pH}$. Therefore, the findings recommended that the adsorption of C.I BB16 on durian shell is favourable in alkaline solutions compared to in neutral and acidic conditions. This is because at the low $\mathrm{pH}$ environment, the competition between excess hydroxyl ions, $\mathrm{H}^{+}$and the cationic groups on the C.I BB16 dye for adsorption sites will make the surface of the adsorbent to exist as a positively charged molecule [40,41].

The adsorption of C.I BB16 investigated the contact time of $30 \mathrm{~min}$ to $240 \mathrm{~min}$. It can be deduced that the adsorption and mineralisation rate of C.I BB16 increases as contact time increases. However, a further increase in contact time did not enhance the C.I BB16 decolorisation process and mineralisation rate. The quick absorption rate at the beginning is attributed to the availability of plentiful active binding sites on the adsorbent surface. Nevertheless, the adsorption process develops an attachment-controlled route owing to less accessibility of adsorption sites as contact time increases. Besides, different durian shell dosages were investigated, ranging from 0.1 to $1 \mathrm{~g}$. The results indicated the decolourisation mineralisation rate of C.I BB16 increased when the durian shell dosage increased. This is assigned to a rise in the adsorptive surface area and the accessibility of more active binding sites on the surface of the durian shell. However, the presence of excess durian shell decreases the adsorption capacity of C.I BB16 - the decrease in total surface area available for C.I BB16 from aggregation or overlying of adsorption sites [42]. Hence, as the dosage of durian shell adsorbent increases, the amount of C.I BB16 adsorbed onto durian shell adsorbent gets reduced, thus causing a decrease in adsorption capacity. In some cases, a further increase in adsorbent dose did not remarkably alter the adsorption capacity. This is owing to the non-accessibility of active sites on the adsorbent and establishment of equilibrium between the C.I BB16 and the durian shell adsorbent [43]. The rate of adsorption and mineralisation rate is a function of the initial concentration of the adsorbate, which makes it an important factor to be considered for effective adsorption-the percentage removal of C.I BB16 decreased with increasing the initial C.I BB16 concentration (Figures 4 and 5). It seems that all adsorbents have a limited number of active sites and at a certain concentration, the active sites become saturated. The initial concentration may provide the necessary driving force to overcome the mass transfer resistance of C.I BB16 between the aqueous and the solid phase [44] - the increase in the initial C.I BB16 concentration also enhances the interaction between the C.I BB16 anion in the aqueous phase and the biomass surface; resulting in higher uptake of C.I BB16 for the given amount of biomass [29,42]. 

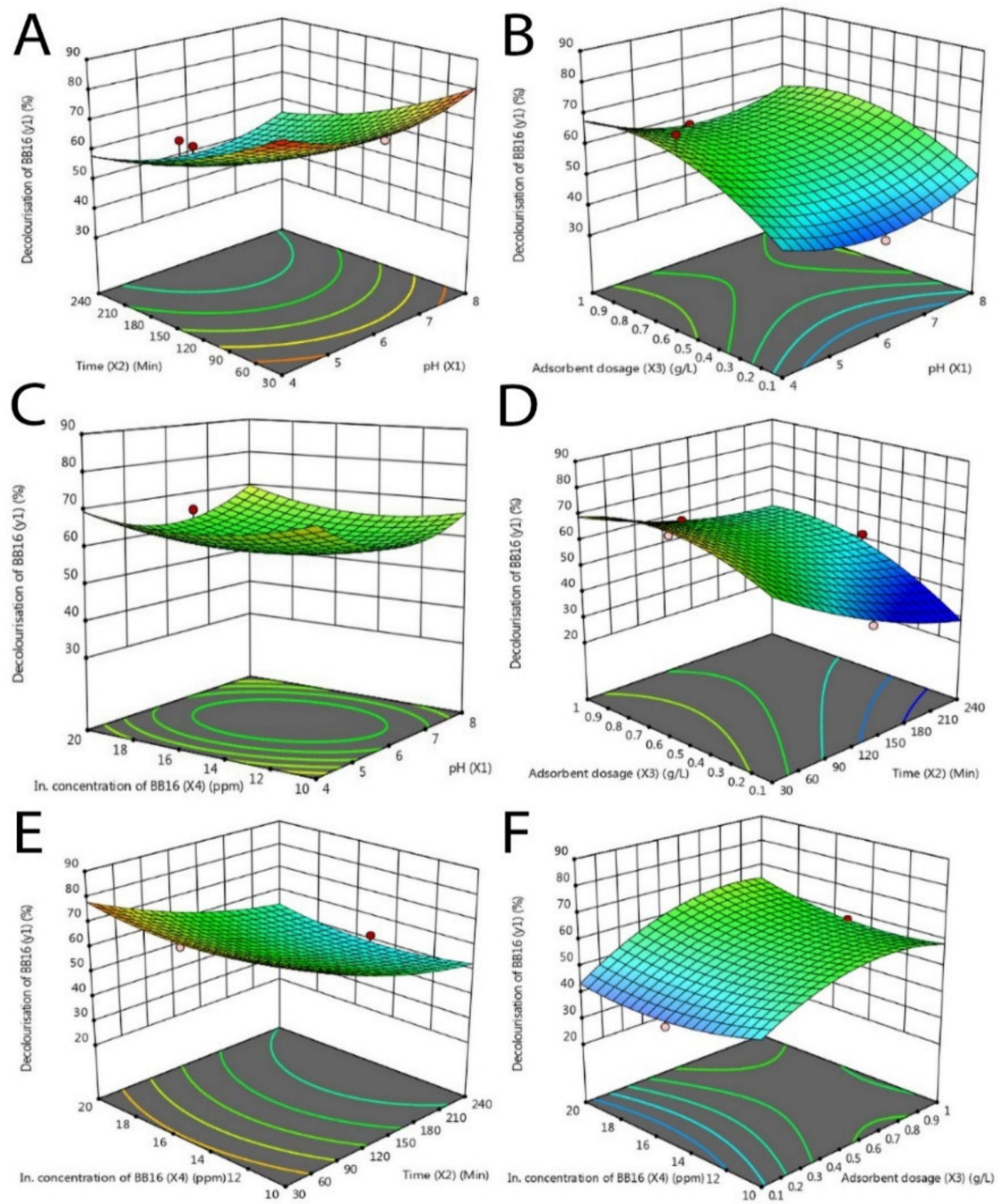

Figure 4. Three-dimensional response surface plot for adsorption of C.I BB16 in aqueous solution; $y_{1}$ : decolourisation; as a response of interaction between independent factors $X_{1}(p H), X_{2}($ Time $), X_{3}$ (adsorbent dosage) and $X_{4}$ (BB16 conc.). (A) interaction between $\mathrm{X} 1, \mathrm{X} 2$; (B) interaction between $\mathrm{X} 1, \mathrm{X} 3$; (C) interaction between $\mathrm{X} 1, \mathrm{X} 4$; (D) interaction between $\mathrm{X} 2, \mathrm{X} 3$; (E) interaction between $\mathrm{X} 2, \mathrm{X} 4$; (F) interaction between $\mathrm{X} 3, \mathrm{X} 4$. 

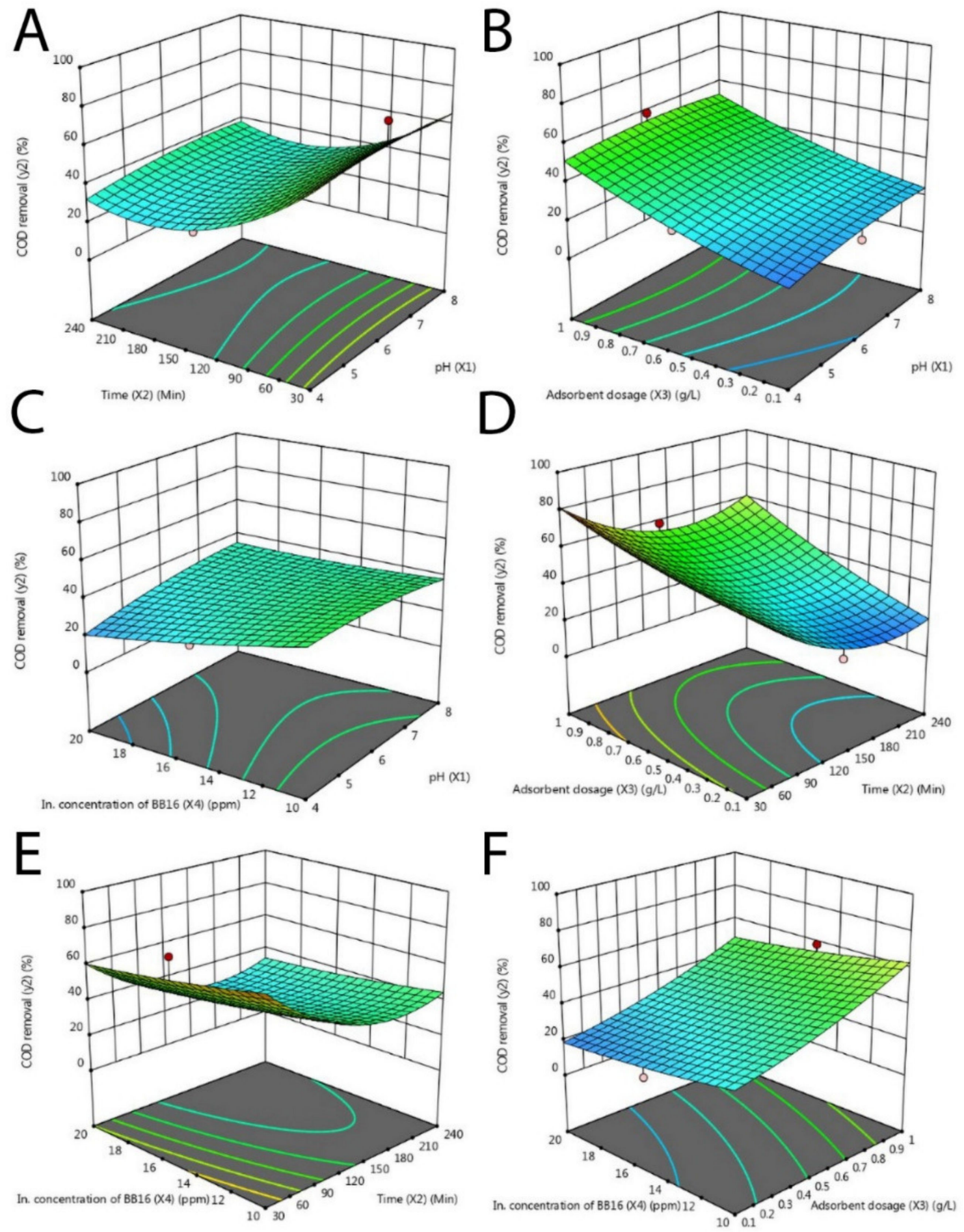

Figure 5. Three-dimensional response surface plot for adsorption of C.I BB16 in aqueous solution;. $y_{2}$ : COD removal; as a response of interaction between independent factors $X_{1}, X_{2}, X_{3}$ and $X_{4} X_{1}(p H)$, $X_{2}$ (Time), $X_{3}$ (adsorbent dosage) and $X_{4}$ (BB16 conc.). (A) interaction between $\mathrm{X} 1, \mathrm{X} 2$; $(\mathbf{B})$ interaction between $\mathrm{X} 1, \mathrm{X} 3$; (C) interaction between $\mathrm{X} 1, \mathrm{X} 4$; (D) interaction between $\mathrm{X} 2, \mathrm{X} 3$; (E) interaction between $\mathrm{X} 2, \mathrm{X} 4 ;(\mathrm{F})$ interaction between $\mathrm{X} 3, \mathrm{X} 4$.

The regression coefficients for the independent factors are illustrated in Table 2. The interactions between these factors and the linear and quadratic regression coefficients were identified by the least square method. $p$-value with $95 \%$ of the confidence level was used as a sign for the importance of each 
independent factor. The results noted that factors $x_{1}, x_{2}, x_{3}$ and $x_{4}$ have a significant quadratic effect on the decolourisation of C.I BB16 $(p<0.0002)$, as well as for COD removal $(\%)$. Moreover, these factors have a synergistic effect on the decolourisation of C.I BB16, final $\mathrm{pH}$ and COD removal (\%) $(p<0.05)$. The second-order model described the relationship between decolourisation and COD reduction and selected factors as given by final equations in terms of actual factors as following:

$$
\begin{aligned}
y_{1}=57.76- & 1.09 x_{1}-12.41 x_{2}+7.73 x_{3}+0.20 x_{4}+7.55 x_{1}^{2} A^{2}+3.90 x_{2}^{2}-7.97 x_{3}^{2} \\
+ & 4.20 x_{4}^{2}-0.26 x_{1} x_{2}-1.63 x_{1} x_{3}+1.32 x_{1} x_{4}+4.65 x_{2} x_{3}+0.36 x_{2} x_{4} \\
& +2.83 x_{3} x_{4} \\
y_{2}=35.79+ & 2.130 x_{1}-14.64 x_{2}+15.55 x_{3}-6.73 x_{4}-2.66 x_{1}^{2}+16.90 x_{2}^{2}+3.31 x_{3}^{2} \\
+ & 1.41 x_{4}^{2}+0.87 x_{1} x_{2}-1.42 x_{1} x_{3}+5.00 x_{1} x_{4}+4.65 x_{2} x_{3}+1.37 x_{2} x_{4} \\
& -0.48 x_{3} x_{4}
\end{aligned}
$$

Table 2. Regression coefficient and their significance of the quadratic model for the adsorption of C.I BB16 in aqueous solution.

\begin{tabular}{ccccccccc}
\hline \multirow{2}{*}{ Term } & \multicolumn{2}{c}{ Coefficient } & \multicolumn{2}{c}{ Standard Error } & \multicolumn{2}{c}{$F$ Value } & \multicolumn{2}{c}{$p$ Value } \\
\cline { 2 - 8 } & $y_{1}$ & $y_{2}$ & $y_{1}$ & $y_{2}$ & $y_{1}$ & $y_{2}$ & $y_{1}$ & $y_{2}$ \\
\hline Model & 57.76 & 35.79 & 3.37 & 5.26 & 11.35 & 11.55 & 0.0002 & 0.0002 \\
$X_{1}$ & -1.09 & 2.13 & 1.31 & 2.05 & 0.69 & 1.08 & 0.4246 & 0.3234 \\
$X_{2}$ & -12.41 & -14.64 & 1.43 & 2.23 & 75.67 & 43.05 & $<0.0001$ & $<0.0001$ \\
$X_{3}$ & 7.73 & 15.55 & 1.25 & 1.96 & 38.04 & 62.86 & $<0.0001$ & $<0.0001$ \\
$X_{4}$ & 0.20 & -6.73 & 1.43 & 2.24 & 0.020 & 9.04 & 0.8895 & 0.0132 \\
$X_{1}^{2}$ & 7.55 & -2.66 & 3.27 & 5.11 & 5.33 & 0.27 & 0.0436 & 0.6146 \\
$X_{2}^{2}$ & 3.90 & 16.90 & 2.58 & 4.04 & 2.28 & 17.54 & 0.1619 & 0.0019 \\
$X_{3}^{2}$ & -7.97 & 3.31 & 4.08 & 6.38 & 3.83 & 0.27 & 0.0790 & 0.6154 \\
$X_{4}^{2}$ & 4.20 & 1.41 & 4.04 & 6.32 & 1.08 & 0.050 & 0.3230 & 0.8275 \\
$X_{1} X_{2}$ & -0.26 & 0.87 & 1.60 & 2.51 & 0.025 & 0.12 & 0.8766 & 0.7353 \\
$X_{1} X_{3}$ & -1.63 & -1.42 & 1.42 & 2.22 & 1.32 & 0.41 & 0.2772 & 0.5354 \\
$X_{1} X_{4}$ & 1.32 & 5.00 & 1.49 & 2.32 & 0.79 & 4.64 & 0.3937 & 0.0566 \\
$X_{2} X_{3}$ & 4.65 & 4.65 & 1.48 & 2.31 & 9.91 & 4.04 & 0.0104 & 0.0721 \\
$X_{2} X_{4}$ & 0.36 & 1.37 & 1.58 & 2.48 & 0.053 & 0.31 & 0.8234 & 0.5920 \\
$X_{3} X_{4}$ & 2.83 & -0.48 & 1.36 & 2.13 & 4.33 & 0.052 & 0.0641 & 0.8250 \\
\hline
\end{tabular}

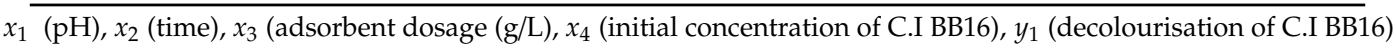
$(\%), y_{2},($ COD removal) $(\%)$.

The summary of the analysis of variance (ANOVA) for the quadratic model is shown in Table 3. It can be deduced that the linear model for decolourisation (\%) and COD removal (\%) was significant at a confidence level of $(p<0.05)$ with determination coefficients $\left(R^{2}\right.$ adj) equal to $R^{2}$ (adj) are 0.8879 and 0.8603 respectively.

Table 3. Analysis of the variance (ANOVA) of the response surface quadratic model for the adsorption of C.I BB16 in aqueous solution.

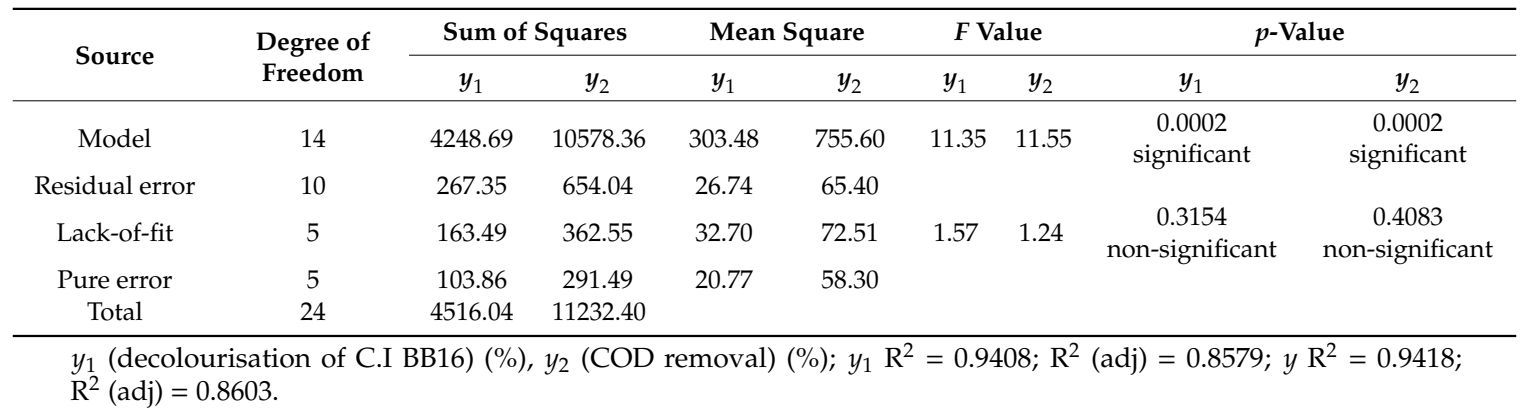


These results ascertain the suitability of the model. The lack of fit for the model was non-significant value $(p>0.05)$, which specifies that the model was predicted for the decolourisation (\%) and COD removal (\%), while was suitable for prediction within the range of the independent factors explored in the current investigation. Moreover, the small residual values are an emblem for the worthy agreement of the experimental data with the mathematical model. RSM with CCD analysis was executed to examine the interactions between the variable factors within the tested range when one factor is an actual factor at the centre point. For the decolourisation (\%) and COD removal (\%), a significant $(p<0.05)$ interaction between $x_{1}(4-8), x_{2}(30-240 \mathrm{~min}), x_{3}(0.1-1 \mathrm{~g})$ and $x_{4}(10-20 \mathrm{ppm})$ as actual factors is shown in Figures 4 and 5. The correlation plot between model-predicted value vs. actual value and residuals vs. run number; A; decolourisation $\left(y_{1}\right), B$; COD removal $\left(y_{2}\right)$ is depicted in Figure 6 . The results revealed a significant correlation between the independent factors and the removal percentage of the dependent variables.
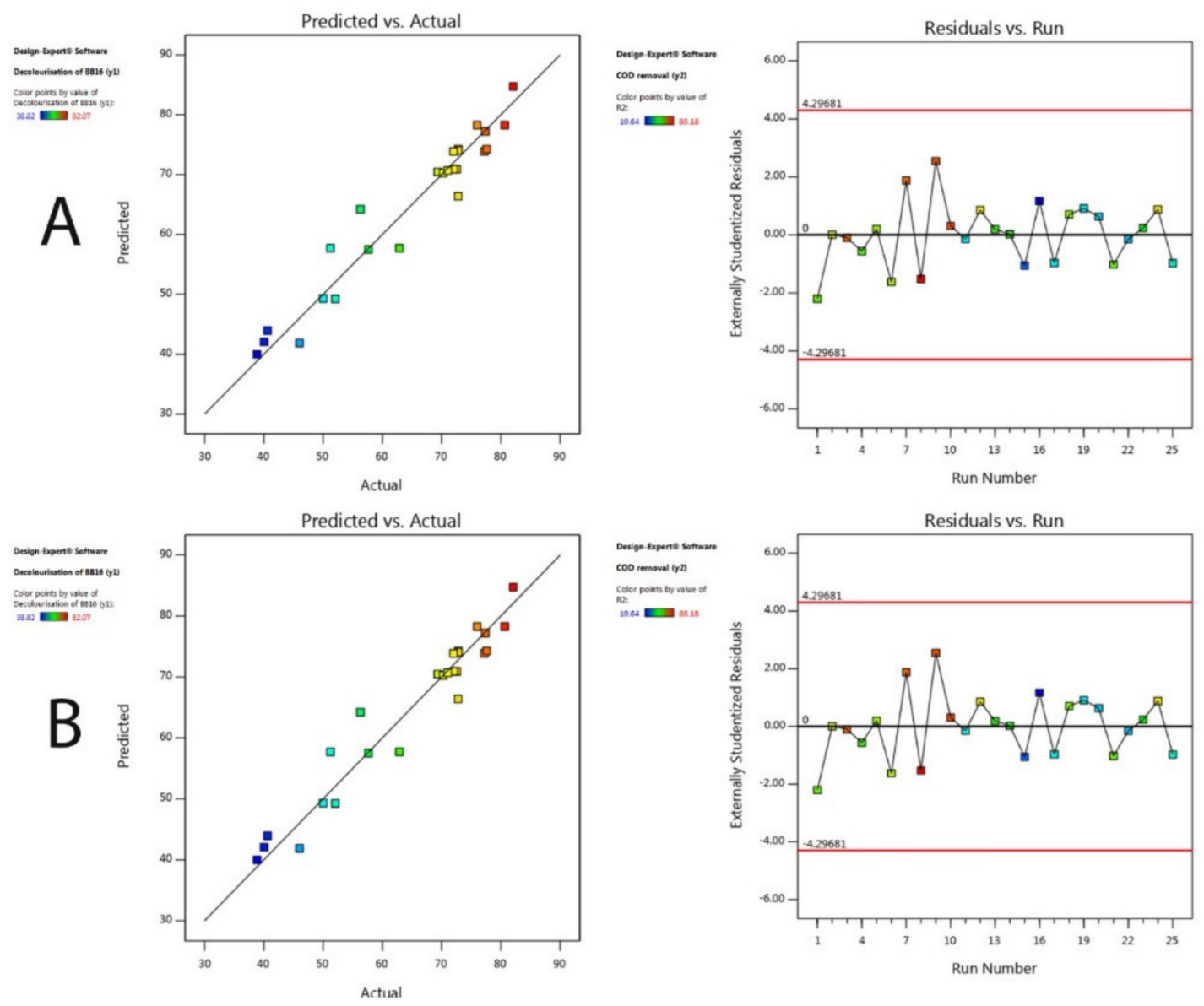

Figure 6. Correlation plot between model-predicted value vs. actual value and residuals vs. run number; (A) decolourisation $\left(y_{1}\right),(\mathbf{B})$ COD removal $\left(y_{2}\right)$.

Validation of the Optimal Parameters

The possible direction for maximising the adsorption of C.I BB16 is by using point optimisation technique with expert design software. The optimal operation parameters of the adsorption of C.I BB16 were recorded at $\mathrm{pH} 8\left(x_{1}\right), 30 \mathrm{~min}\left(x_{2}\right), 1.0 \mathrm{~g}$ of adsorbent $\left(x_{3}\right)$ and $15 \mathrm{ppm}$ of C.I BB16 $\left(x_{4}\right)$. At the optimal conditions of the adsorption of C.I BB16, the independent factors interacted significantly $(p<0.05)$ (Table 4). 
Table 4. The best operating parameters for the adsorption of C.I BB16 in aqueous solution.

\begin{tabular}{ccccccc}
\hline Responses & $x_{1}$ & $x_{2}$ & $x_{3}$ & $x_{4}$ & $\begin{array}{c}\text { Predicted } \\
\text { Results }\end{array}$ & $\begin{array}{c}\text { Experimental } \\
\text { Results }\end{array}$ \\
\hline$y_{1}$ & 8.00 & 30.00 & 1.00 & 15.00 & 77.61 & 74.26 \\
\hline$y_{2}$ & & & & & 80.60 & 78.72 \\
\hline
\end{tabular}

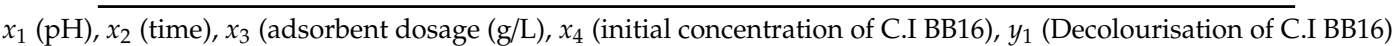
$(\%), y_{2}$ (COD removal) (\%).

This specifies that interaction effects occur as a consequence of one factor influenced by another factor. The $\mathrm{pH}$, time, durian shell adsorbent dosage and initial concentration of C.I BB16 act together very well to attain the maximum decolourisation and COD removal rate. The percentage error among the actual and predicted values was recorded less than 5\% (confidence level 95\%) which indicates that no substantial difference was observed and therefore, affirms that the RSM method was suitable to optimise the operational settings of adsorption of C.I BB16. In comparison with the previous studies by Mohammed et al. [19], it was noted that durian shell sorbents achieved $95.91 \%$ and $97.81 \%$ decolourisation of C. I Methylene Blue and C. I Brilliant Green, respectively. The differences in the results occurred as these factors were investigated individually, whereas, in their study, the interactions between these independent factors were not considered. In the current investigations, the optimisation of the adsorption of C.I BB16 achieved more than $77.61 \%$, which designate the role of RSM design in attaining the maximum and optimum conditions for the adsorption of C.I BB16. The high effectiveness of adsorption of C.I BB16 in reaction to the examined independent variables would be described based on the occurrence of a significant synergic relationship between the parameters. These outcomes are constant with the authors in the literature, who directed that the investigated factors play a significant part in the adsorption of C.I BB16, Mondal et al. [29]. The optimisation process using RSM regulates the best operation parameters to reach high adsorption efficiency.

\subsection{Mechanism of Adsorption}

To describe the nature of adsorption, the mechanism of adsorption was studied by interpretation of the intraparticle diffusion (Figure 7).

The key factors that control the rate of adsorption can be affected by the adsorption at the internal and external surface which depends on the binding process, transfer of mass through the external boundary and the adsorbate diffusion to the adsorption site across liquid pores or solid surface. Therefore, the decolourisation (77.61\%) and COD removal (80.60\%) at $\mathrm{pH} 8,30 \mathrm{~min}, 1 \mathrm{~g} / \mathrm{L}$ of durian shell dosage and 15 ppm of C.I BB16 were achieved based on independent factors explored in the current investigation. The competition between hydroxyl ions, $\mathrm{H}+$ and the cationic groups on the C.I BB16 dye for adsorption sites will change the surface of adsorbent charged molecule positively or negatively depends on $\mathrm{pH}$ value, which will improve the positively charged dye cations through electrostatic forces of attraction. Durian is the member of the Bombacaceae family which is largely found in Malaysia and Indonesia of Southeast Asia. Durian peels are the waste materials of durian and consist of a lot of polysaccharides, cellulose and lignin. Those ingredients have different active functional groups that relatively affect the adsorption of analyses (dye, metal), via interactions occurred between solid surfaces and adsorbate (Ahmad and Danish, 2018); structure of the adsorbate and the functional groups of the adsorbent surfaces. Durian adsorption of C.I BB16 molecules results from hydrogen bonding between $\mathrm{OH}$ and $\mathrm{NH}_{2}$ groups of dye molecules and $\mathrm{OH}$ groups of durian peels and electrostatic interaction between the negatively charged durian surface and cationic dye. Referred to FTIR spectra, the results showed that carboxylic acids (-COOH) and the hydroxyl groups were available on the sites because of interactions of the surface of the peel. These functional groups could control the uptake of positively charged C.I BB16 molecule. Whereas, electrostatic attraction,

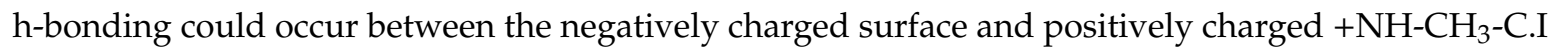
BB16 molecules [45,46]. 


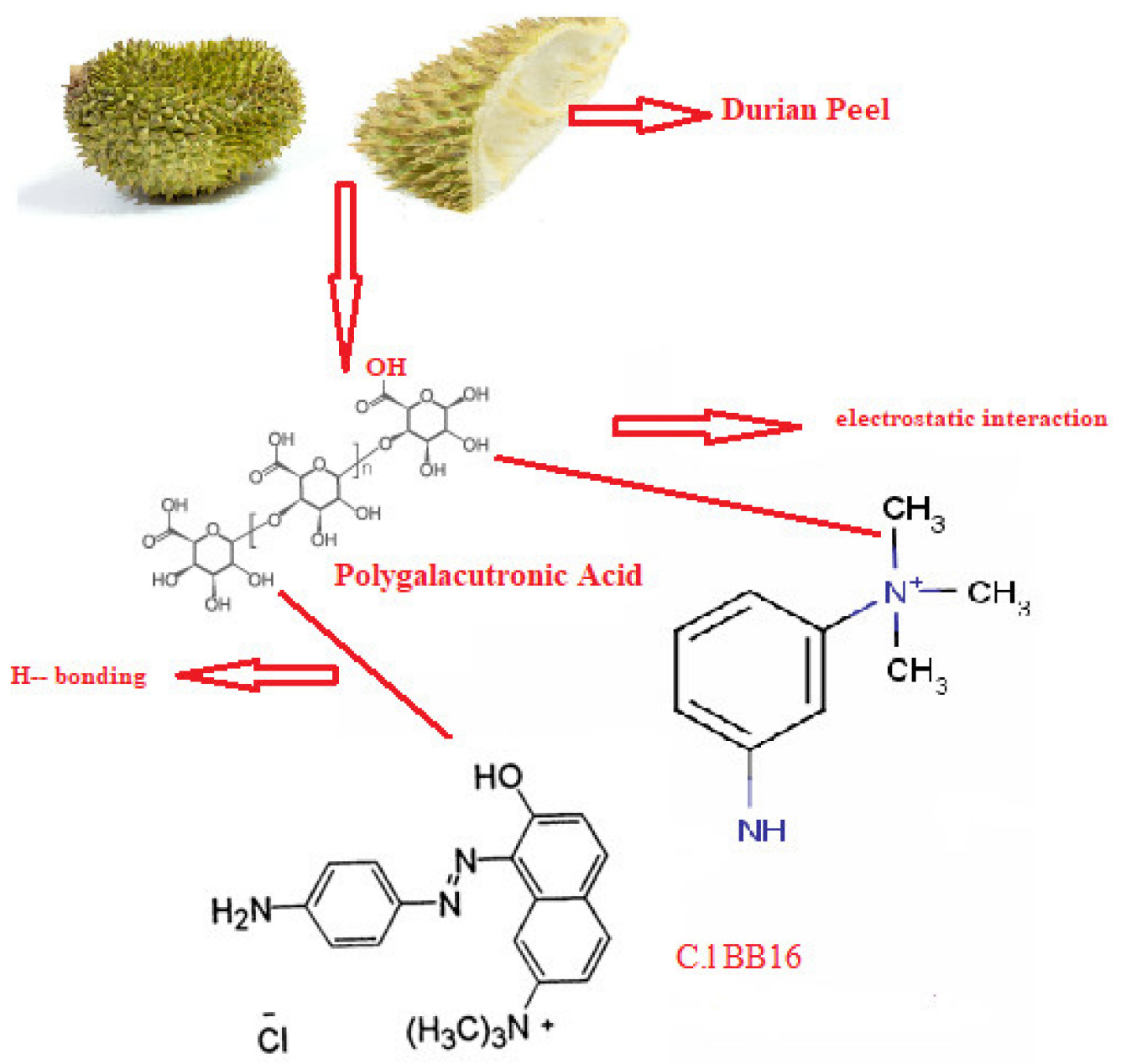

Figure 7. Removal mechanism of C.I BB16 using durian shell adsorbent.

3.4. Techno-Economic Analysis for Preparation and Application of Durian Shell for Hair Dye Greywater Treatment

The durian shell adsorbent preparation and application diagram was designed using SuperPro Designer, as presented in Figure $8 \mathrm{~b}$. The suggested adsorbent preparation and application unit is proposed to have consisted of four stages. In stage $A$, the raw materials of durian shell adsorbent are collected, washed and granulated as well as adsorbent dose preparation is done. In stage B, the hair dye greywater is subjected to primary treatment to remove the large suspended solids, which might affect the adsorption process negatively. The main treatment process of the hair dye greywater by the adsorption using durian shell adsorbent is supposed to be performed in Stage C. Finally, the stage proposes the post-treatment process for the treated hair dye wastewater which is safe for disposal while the durian shell might be used as the substrate for fuel or biohydrogen production because of the high contents of the carbohydrates.

The FCE represents all equipment purchase cost, process piping, equipment installation, electrical systems, instrumentation and controls, buildings, construction and yard improvements as well as the WCC which might be up to $6.5 \%$ of FCE as described by Han et al. [46]. Therefore, the FCE for designing a preparation and coagulation unit for wastewater treatment with $1000 \mathrm{~m}^{3} /$ day capacity could be up to USD 32,000.00 (Table 5). 


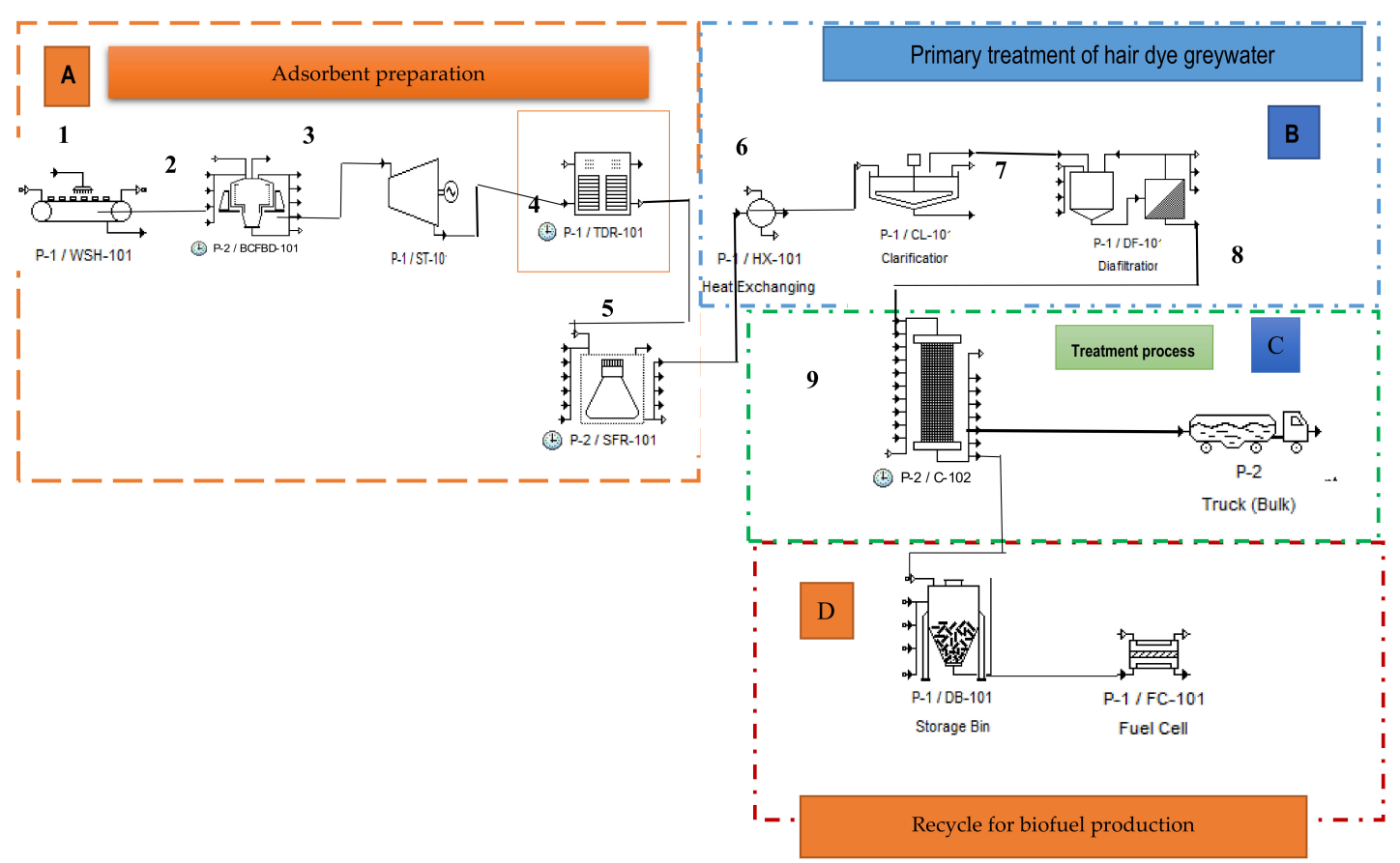

(a)

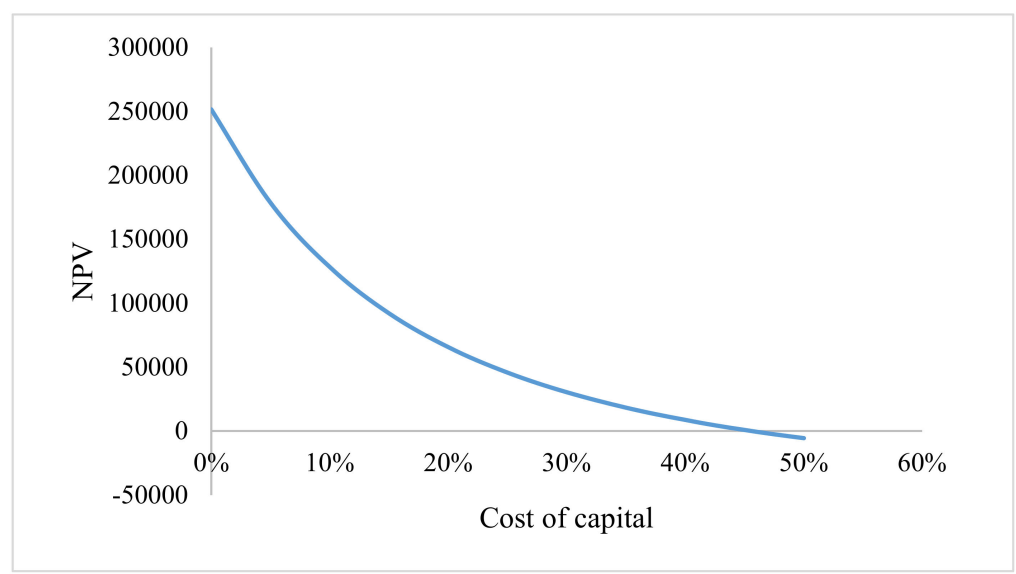

(b)

Figure 8. (a) The flowchart for preparation and application of durian shell adsorbent for C.I BB16 wastewater treatment. (b) Internal rate of return (IRR) of durian shell adsorbent production.

The additional costs for the treatment process might reach $50 \%$ of the equipment cost, which was equivalent to USD 16,000.00 [47]. The TCI of the plant might go up to USD 48,000.00 WCC, which was estimated to be $6.5 \%$ of the FCE to the tune of about USD 3120.00 Therefore, according to Equation (1), the TCI of USD 51,120.00 could be calculated. The techno-economic analysis is one of the best methods for determining the effectiveness of any alternative method for treating environmental pollution because this process provides more details for the total cost of the treatment process for specific pollution in comparison to the current technologies [47]. It has also been used to estimate the $\mathrm{H}_{2}$ production by fungi from food wastes and provided very accurate information on the total cost $[44,48]$. 
Table 5. Fixed capital estimate (FCE) for preparation and application of durian shell adsorbent for hair dye wastewater treatment.

\begin{tabular}{|c|c|c|c|c|}
\hline No & Item Code * & Item & Percentage of FCE & Cost \\
\hline 1 & P-1/WSH-101 & Washing tank & \multirow{9}{*}{$62.5 \%$} & \multirow{5}{*}{$10,000.00$} \\
\hline 2 & P-2/BCFBD-101 & Basket centrifuge & & \\
\hline 3 & P-1/ST-10 & Straight flow steam Turbine Generator & & \\
\hline 4 & P-1/TDR-101 & Tray Drying & & \\
\hline 5 & P-2/SFR-101 & Shake flasks & & \\
\hline 6 & P-1/HX-101 & Heat Exchange & & 1000.00 \\
\hline 7 & P-1/CL-101 & Clarification & & 2000.00 \\
\hline 8 & P-1/DF-101 & Dia-filtration & & 3000.00 \\
\hline \multirow[t]{2}{*}{9} & P-2/C-102 PBA & Adsorption unit & & 4000.00 \\
\hline & & Total Equipment purchase cost & & $20,000.00$ \\
\hline 10 & & Equipment installation & 3.13 & 1000.00 \\
\hline 11 & & Process piping & 3.13 & 1000.00 \\
\hline 12 & & strumentation and controls & 6.25 & 2000.00 \\
\hline 13 & & Electrical systems & 3.13 & 1000.00 \\
\hline 14 & & Buildings & 15.63 & 5000.00 \\
\hline 15 & & Yard improvements & 3.13 & 1000.00 \\
\hline \multirow[t]{2}{*}{16} & & Construction & 3.13 & 1000.00 \\
\hline & & TOTAL & & $32,000.00$ \\
\hline
\end{tabular}

* Refer the item code to Figure 8a.

\subsubsection{Annual Operation Cost}

The $C_{R M}$ is the cost of durian shell. The durian shell as well as the chemicals required for preparation of the durian shell to be used as a coagulant was supplied by a local supplier. The $C_{U}$ include the cost of electricity and water which are required for the preparation of durian shell adsorbent and the wastewater treatment and was estimated based on the price for each unit in the local currency. The $C_{W G}$ represents the final solid waste generated from the coagulation treatment unit of the wastewater which is considered as a biomass yield with high concentrations of carbohydrates and could be used as bio-sorbents for wastewater treatment as well as for fuel production. Moreover, the generated wastewater from the adsorption unit could be safe for disposal.

Table 6 shows the annual operation cost for the preparation of durian shell adsorbent. The raw material cost $\left(C_{R M}\right)$ was USD zero/year (since the durian shells are agriculture wastes and no chemical are required for the preparation). In the current study, the best dose for achieving high COS, turbidity and TSS removal are $1 \mathrm{~g} / \mathrm{L}$. The suggested design here manages with $1000 \mathrm{~m}^{3}$ per day for 240 days per year. The experiments confirmed that $1 \mathrm{~kg}$ of raw durian shell generates $500 \mathrm{~g}$ pure coagulant. In order to deal with $240,000 \mathrm{~m}^{3}$ per year, the process should deal with 480 tons of raw durian shell to generate 240 tons ( $1000 \mathrm{~kg} /$ day) of pure coagulant to treat the quantities required per year. The total cost of utilities is estimated to be USD 5000.00/year as estimated by Han et al. [48] in China, which has a similar cost for water and electricity as Malaysia. The costs of maintenance, insurance and labour as well as the operating labour cost, were based on the estimation that each process operation using $100 \mathrm{~kg}$ of raw durian shell to produce $50 \mathrm{~kg}$ of pure adsorbent daily required only one operator with an average salary of $6000.00 \mathrm{USD} /$ year per operator $(\max 3 \mathrm{~h} /$ day). The maintenance and insurance were estimated at $2 \%$ and $1 \%$ of the FCC, respectively, according to Vlysidis et al. [47] and Ljunggren and Zacchi [49]. It can be concluded that the AOC is USD 11,960.00/year. 
Table 6. Annual operation cost of the preparation and application of durian shell adsorbent for hair dye wastewater treatment.

\begin{tabular}{cccccc}
\hline & Component & Price & Unit & Quantity & Cost (USD) \\
\hline $\begin{array}{c}\text { Raw material } \\
\text { (chemicals) }\end{array}$ & Cassava peels & Free & USD $/ \mathrm{kg}$ & 48 ton/year & 0 \\
\hline \multirow{2}{*}{ Utilities } & Electricity & 0.04 & $\mathrm{USD} / \mathrm{kWh}$ & 100,000 & 4000.00 \\
\cline { 2 - 6 } & Water & 0.01 & $\mathrm{USD} / \mathrm{m}^{3}$ & 100,000 & 1000.00 \\
\hline \multirow{2}{*}{ Other costs } & Labour & 6000.00 & $\mathrm{USD} / \mathrm{employee}$ & 1 & 6000.00 \\
\cline { 2 - 6 } & Maintenance & 2 & $\%$ of FCE & & 640.00 \\
\cline { 2 - 6 } & Insurance & 1 & $\%$ of FCE & & 320.00 \\
\hline
\end{tabular}

\subsubsection{Annual Profitability and Revenue}

The revenue for the preparation and application of durian shell adsorbent is generated from selling the adsorbent for the treatment of different wastewater. The current price of chemical adsorbent might reach USD 261.81.00 per tons of Honeydew peels-activated carbon (HDP-AC) and the commercial market of the activated carbon price is USD 1000.00/tons [50]. The machines in Table 5, have $100 \mathrm{~kg}$ of the capacity for each operation which takes place within a day. Therefore, the total capacity per year is to produce 240 tons of pure durian shell adsorbent. The total net of the raw durian shell in the current work was $500 \mathrm{~g}$ per $1000 \mathrm{~g}$ of the raw materials. Therefore, the revenue for each production process is $1000 \mathrm{~kg}$ of the pure durian shell adsorbent which gives USD 62834.00 of the revenue. The annual revenue of USD $62,834.00$ could be estimated. Considering the $15 \%$ local tax in Malaysia, this is estimated to be USD 9425.00 and the annual operation cost is USD 11,960.00, the annual profitability (after the tax) of the durian shell adsorbent is USD 41,499.24 (Table 7a). Based on Equation (9), the specific cost of pure durian shell adsorbent production is estimated to be USD 172.71 per ton which is lower than the market price of honeydew peels-activated carbon (HDP-AC) (USD 261.81) and the commercial market of activated carbon price which is USD 1000.00/tons.

Table 7. (a) Annual profitability of the preparation and application of durian shell adsorbent for hair dye wastewater treatment. (b) Cost factors associated with the adsorption of C.I BB16 from the hair dye wastewater by durian shell adsorbent for hair dye wastewater in comparison to the physical and chemical treatment process.

\begin{tabular}{cccc}
\hline & (a) & & \\
\hline & Price & Quantity & Value \\
\hline Durian shell & USD 261.81/Ton & 240 Ton & $62,834.00$ \\
Annual revenue & & & $62,834.00$ \\
Annual operation cost & & & $11,960.00$ \\
Local tax & & & 9425.00 \\
Annual profitability & (b) & & \\
\hline Cost Factor & Physical & Chemical & Durian Shell Adsorbent \\
\hline Heat and energy requirement & 2 & 1 & 0 \\
Chemicals (acid/alkali/ammonia) & 0 & 2 & 0 \\
pH neutralisation & 0 & 2 & 0 \\
Detoxification/conditioning & 1 & 2 & 0 \\
Special reactor construction & 2 & 2 & 0 \\
Total & 5 & 9 & 0 \\
\hline
\end{tabular}


In this study, the pure durian shell adsorbent production unit was economically evaluated according to the internal rate of return (IRR), net present value (NPV) as well as the payback period (PBP) of 10 years of the lifetime. The IRR (the efficiency of the investment) was $45.62 \%$ in the current study (Figure 8b). Based on the analysis given above, the durian shell exhibited high efficiency for adsorption of hair dye wastewater. Therefore, the techno-economic analysis as described in the current work is economically feasible by $45.62 \%$ of the IRR. It might provide alternative methods for chemical and physical coagulation for wastewater treatment (Table $7 \mathrm{~b}$ ).

\section{Conclusions}

It can be concluded that an adsorbent was successfully produced via the durian shell and successfully showed high efficiency for the adsorption of C.I BB16 - the optimal operating factors for adsorption C.I BB16 recorded at $\mathrm{pH} 8$, time (30 min), durian shell dosage $(1 \mathrm{~g} / \mathrm{L})$, and $15 \mathrm{mg} / \mathrm{L}$ of C.I BB16 concentrations where 77.61 vs. 74.26 (\%) of C.I BB16 removal and 80.60 vs. 78.72 (\%) of COD removal was the observed and predicted results recorded with an $R^{2}$ coefficient of 0.94 , respectively. The process is very economically feasible with $45.62 \%$ of the internal rate of return (IRR). These findings indicate that the durian shell adsorbent has great potential to be applied as a low cost and eco-friendly adsorbent in the adsorption process of dyes in aqueous solution. The utilisation of durian shells as an adsorbent also helped in reducing solid waste in agriculture.

Author Contributions: Conceptualization, A.A.-G.; methodology, Y.G. and M.M.A.; software, M.A.-S.; validation, A.A.-G., M.A.M. and R.M.S.R.M.; formal analysis, A.A.-G.; investigation, S.A.; resources, A.A.-G.; data curation, Y.G.; writing-E.N., A.A.-G.; writing—review and editing, M.A.M.; visualization, A.A.-G.; supervision, R.M.S.R.M.; project administration, M.A.M. All authors have read and agreed to the published version of the manuscript.

Funding: This research received no external funding.

Acknowledgments: This research was funded by the technical \& financial support from UNITEN RMC Internal Research Grant: RJO 10517919/iRMC/Publication and Ministry of Education Malaysia (KPM) through the Fundamental Research Grant Scheme (FRGS) with reference code: FRGS/1/2019/WAB05/UTHM/02/5 (Modification of Bead Adsorbents with Ceramic Sanitary Ware Waste (CSWW) and Chitosan for Laundry Greywater (LGW) Safe Disposal) as financial support for this research project.

Conflicts of Interest: The authors declare no conflict of interest.

\section{References}

1. Fernandes, N.C.; Brito, L.B.; Costa, G.; Taveira, S.F.; Cunha-Filho, M.; Oliveira, G.A.R.; Marreto, R. Removal of azo dye using Fenton and Fenton-like processes: Evaluation of process factors by Box-Behnken design and ecotoxicity tests. Chem. Interact. 2018, 291, 47-54. [CrossRef] [PubMed]

2. Joseph, J.; Radhakrishnan, R.C.; Johnson, J.K.; Joy, S.P.; Thomas, J. Ion-exchange mediated removal of cationic dye-stuffs from water using ammonium phosphomolybdate. Mater. Chem. Phys. 2020, 242, 122488. [CrossRef]

3. Rosu, C.M.; Vochita, G.; Mihășan, M.; Avădanei, M.; Mihai, C.; Gherghel, D. Performances of Pichia kudriavzevii in decolorization, biodegradation, and detoxification of C.I. Basic Blue 41 under optimized cultural conditions. Environ. Sci. Pollut. Res. 2018, 26, 431-445. [CrossRef]

4. Aguilar, Z.G.; Brillas, E.; Salazar, M.; Nava, J.L.; Sirés, I.; Sadornil, I.S. Evidence of Fenton-like reaction with active chlorine during the electrocatalytic oxidation of Acid Yellow 36 azo dye with Ir-Sn-Sb oxide anode in the presence of iron ion. Appl. Catal. B Environ. 2017, 206, 44-52. [CrossRef]

5. Obiora-Okafo, I.A.; Onukwuli, O.D. Optimization of Coagulation-Flocculation for Colour Removal from Azo Dye Using Natural Polyemers: Response Surface Methodological Approach. Niger. J. Technol. 2017, 36, 482-495. [CrossRef]

6. Isarain-Chávez, E.; Baro, M.D.; Rossinyol, E.; Morales-Ortiz, U.; Sort, J.; Brillas, E.; Pellicer, E. Comparative electrochemical oxidation of methyl orange azo dye using Ti/Ir-Pb, Ti//r-Sn, Ti/Ru-Pb, Ti/Pt-Pd and Ti/RuO2 anodes. Electrochim. Acta 2017, 244, 199-208. [CrossRef] 
7. Castro, F.D.; Bassin, J.P.; Dezotti, M. Treatment of a simulated textile wastewater containing the Reactive Orange 16 azo dye by a combination of ozonation and moving-bed biofilm reactor: Evaluating the performance, toxicity, and oxidation by-products. Environ. Sci. Pollut. Res. 2016, 24, 6307-6316. [CrossRef]

8. Bahia, M.; Passos, F.; Adarme, O.F.H.; Aquino, S.F.; Silva, S.Q. Anaerobic-Aerobic Combined System for the Biological Treatment of Azo Dye Solution Using Residual Yeast. Water Environ. Res. 2018, 90, 729-737. [CrossRef]

9. Zong, E.; Liu, X.; Jiang, J.; Fu, S.; Chu, F. Preparation and characterization of zirconia-loaded lignocellulosic butanol residue as a biosorbent for phosphate removal from aqueous solution. Appl. Surf. Sci. 2016, 387, 419-430. [CrossRef]

10. Pathak, P.; Gupta, D.K. Strontium contamination in the environment. In The Handbook of Environmental Chemistry; Springer International Publishing: Cham, Switzerland, 2020. [CrossRef]

11. Gonçalves, J.A.C.; Schwantes, D.; Campagnolo, M.A.; Dragunski, D.C.; Tarley, C.R.T.; Silva, A.K.D.S. Removal of toxic metals using endocarp of açaí berry as biosorbent. Water Sci. Technol. 2018, 77, 1547-1557. [CrossRef]

12. Chan, S.-L.; Tan, Y.P.; Abdullah, A.H.; Ong, S.-T. Equilibrium, kinetic and thermodynamic studies of a new potential biosorbent for the removal of Basic Blue 3 and Congo Red dyes: Pineapple (Ananas comosus) plant stem. J. Taiwan Inst. Chem. Eng. 2016, 61, 306-315. [CrossRef]

13. Jain, S.N.; Gogate, P.R. Acid Blue 113 removal from aqueous solution using novel biosorbent based on $\mathrm{NaOH}$ treated and surfactant modified fallen leaves of Prunus Dulcis. J. Environ. Chem. Eng. 2017, 5, 3384-3394. [CrossRef]

14. Heraldy, E.; Lestari, W.W.; Permatasari, D.; Arimurti, D.D. Biosorbent from tomato waste and apple juice residue for lead removal. J. Environ. Chem. Eng. 2018, 6, 1201-1208. [CrossRef]

15. Ma, L.; Jiang, C.; Lin, Z.-Y.; Zou, Z. Microwave-Hydrothermal Treated Grape Peel as an Efficient Biosorbent for Methylene Blue Removal. Int. J. Environ. Res. Public Heal. 2018, 15, 239. [CrossRef]

16. Machrouhi, A.; Farnane, M.; Elhalil, A.; Abdennouri, M.; Tounsadi, H.; Barka, N. Heavy metals adsorption by Thapsia transtagana stems powder: Kinetics, equilibrium and thermodynamics. Moroc. J. Chem. 2019, 7 , 98-110.

17. Yildirim, A.; Acay, H.; Baran, F. Synthesis and characterisation of mushroom-based nanocomposite and its efficiency on dye biosorption via antimicrobial activity. Int. J. Environ. Anal. Chem. 2020, 1-18. [CrossRef]

18. Saueprasearsit, P. Adsorption of chromium $(\mathrm{Cr}+6)$ using durian peel. Int. Conf. Biotechnol. Environ. Manag. 2011, 18, 33-38.

19. Mohammed, S.A.; Najib, N.W.A.Z.; Muniandi, V. Durian rind as a low cost adsorbent. Int. J. Civ. Environ. Eng. 2012, 12, 51-56.

20. Foo, K.Y.; Hameed, B. Transformation of durian biomass into a highly valuable end commodity: Trends and opportunities. Biomass Bioenergy 2011, 35, 2470-2478. [CrossRef]

21. Koay, S.C.; Subramanian, V.; Chan, M.Y.; Pang, M.M.; Tshai, K.Y.; Cheah, K.H. Preparation and Characterization of Wood Plastic Composite Made Up of Durian Husk Fiber and Recycled Polystyrene Foam. MATEC Web Conf. 2018, 152, 02019. [CrossRef]

22. Lazim, Z.M.; Hadibarata, T.; Othman, M.H.D.; Yusop, Z.; Wirasnita, R.; Nor, N.M. Utilization of durian peel as potential adsorbent for bisphenol a removal in aquoeus solution. J. Teknol. 2015, 74, 109-115. [CrossRef]

23. Méndez, A.A.; Pena, L.B.; Curto, L.M.; Sciorra, M.D.; Ulloa, R.M.; Aguilar, S.M.G.; Ramos, J.M.V.; Gallego, S.M. Optimization of recombinant maize CDKA;1 and CycD6;1 production in Escherichia coli by response surface methodology. Protein Expr. Purif. 2019, 165, 105483. [CrossRef] [PubMed]

24. Ciric, A.R.; Krajnc, B.; Heath, D.; Ogrinc, N. Response surface methodology and artificial neural network approach for the optimization of ultrasound-assisted extraction of polyphenols from garlic. Food Chem. Toxicol. 2020, 135, 110976. [CrossRef]

25. Ahmad, M.A.; Hamid, S.R.A.; Yusop, M.F.M.; Aziz, H.B.A. Optimization of microwave-assisted durian seed based activated carbon preparation conditions for methylene blue dye removal. In Proceedings of the International Conference of Global Network for Innovative Technology and Awam International Conference in Civil Engineering (Ignite-Aicce\&Rsquo;17): Malaysia Sustainable Technology and Practice for Infrastructure and Community Resilience, Penang, Malaysia, 8-10 August 2017; Volume 1892, p. 040019.

26. Reshadi, M.A.M.; Bazargan, A.; McKay, G. A review of the application of adsorbents for landfill leachate treatment: Focus on magnetic adsorption. Sci. Total. Environ. 2020, 731, 138863. [CrossRef] [PubMed] 
27. Fahimmunisha, B.A.; Ishwarya, R.; AlSalhi, M.; Devanesan, S.; Govindarajan, M.; Vaseeharan, B. Green fabrication, characterization and antibacterial potential of zinc oxide nanoparticles using Aloe socotrina leaf extract: A novel drug delivery approach. J. Drug Deliv. Sci. Technol. 2020, 55, 101465. [CrossRef]

28. Barrera, H.; Cruz-Olivares, J.; Frontana-Uribe, B.A.; Gómez-Díaz, A.; Reyes-Romero, P.G.; Barrera-Diaz, C.E. Electro-Oxidation-Plasma Treatment for Azo Dye Carmoisine (Acid Red 14) in an Aqueous Solution. Materials 2020, 13, 1463. [CrossRef]

29. Mondal, N.K.; Samanta, A.; Roy, P.; Das, B. Optimization study of adsorption parameters for removal of $\mathrm{Cr}(\mathrm{VI})$ using Magnolia leaf biomass by response surface methodology. Sustain. Water Resour. Manag. 2019, 5, 1627-1639. [CrossRef]

30. Sanati, A.M.; Kamari, S.; Ghorbani, F. Application of response surface methodology for optimization of cadmium adsorption from aqueous solutions by Fe3O4@SiO2@APTMS core-shell magnetic nanohybrid. Surf. Interfaces 2019, 17, 100374. [CrossRef]

31. Petrović, M.S.; Šoštarić, T.; Stojanović, M.D.; Milojković, J.; Mihajlović, M.; Stanojević, M.; Stanković, S. Removal of $\mathrm{Pb}^{2+}$ ions by raw corn silk (Zea mays L.) as a novel biosorbent. J. Taiwan Inst. Chem. Eng. 2016, 58, 407-416. [CrossRef]

32. Ben Amar, M.; Walha, K.; Salvadó, V. Evaluation of Olive Stones for $\mathrm{Cd}(\mathrm{II}), \mathrm{Cu}(\mathrm{II}), \mathrm{Pb}(\mathrm{II})$ and $\mathrm{Cr}(\mathrm{VI})$ Biosorption from Aqueous Solution: Equilibrium and Kinetics. Int. J. Environ. Res. 2020, 14, 193-204. [CrossRef]

33. Kwan, T.H.; Pleissner, D.; Lau, K.Y.; Venus, J.; Pommeret, A.; Lin, C.S.K. Techno-economic analysis of a food waste valorization process via microalgae cultivation and co-production of plasticizer, lactic acid and animal feed from algal biomass and food waste. Bioresour. Technol. 2015, 198, 292-299. [CrossRef] [PubMed]

34. Han, W.; Fang, J.; Liu, Z.; Tang, J. Techno-economic evaluation of a combined bioprocess for fermentative hydrogen production from food waste. Bioresour. Technol. 2016, 202, 107-112. [CrossRef] [PubMed]

35. Han, W.; Hu, Y.; Li, S.; Huang, J.; Nie, Q.; Zhao, H.; Tang, J. Simultaneous dark fermentative hydrogen and ethanol production from waste bread in a mixed packed tank reactor. J. Clean. Prod. 2017, 141, 608-611. [CrossRef]

36. Bulgariu, L.; Bulgariu, D. Functionalized soy waste biomass-A novel environmental-friendly biosorbent for the removal of heavy metals from aqueous solution. J. Clean. Prod. 2018, 197, 875-885. [CrossRef]

37. Sharma, D.; Sabela, M.; Kanchi, S.; Bisetty, K.; Skelton, A.A.; Honarparvar, B. Green synthesis, characterization and electrochemical sensing of silymarin by ZnO nanoparticles: Experimental and DFT studies. J. Electroanal. Chem. 2018, 808, 160-172. [CrossRef]

38. Tham, Y.; Latif, P.A.; Abdullah, A.M.; Shamala-Devi, A.; Taufiq-Yap, Y. Performances of toluene removal by activated carbon derived from durian shell. Bioresour. Technol. 2011, 102, 724-728. [CrossRef]

39. Latib, E.H.A.; Mustfha, M.S.; Sufian, S.; Shaari, K.Z.K. Methylene Blue Dye Adsorption to Durian Shell Activated Carbon. Key Eng. Mater. 2013, 594-595, 350-355. [CrossRef]

40. Naushad, M.; Alqadami, A.A.; Alothman, Z.A.; Alsohaimi, I.H.; Algamdi, M.S.; Aldawsari, A.M. Adsorption kinetics, isotherm and reusability studies for the removal of cationic dye from aqueous medium using arginine modified activated carbon. J. Mol. Liq. 2019, 293, 111442. [CrossRef]

41. Albadarin, A.B.; Collins, M.N.; Naushad, M.; Shirazian, S.; Walker, G.; Mangwandi, C. Activated lignin-chitosan extruded blends for efficient adsorption of methylene blue. Chem. Eng. J. 2017, 307, 264-272. [CrossRef]

42. Bahrami, M.; Amiri, M.; Bagheri, F. Optimization of the lead removal from aqueous solution using two starch based adsorbents: Design of experiments using response surface methodology (RSM). J. Environ. Chem. Eng. 2019, 7, 102793. [CrossRef]

43. Sun, Y.; Yang, Y.; Yang, M.; Yu, F.; Ma, J. Response surface methodological evaluation and optimization for adsorption removal of ciprofloxacin onto graphene hydrogel. J. Mol. Liq. 2019, 284, 124-130. [CrossRef]

44. Abukhadra, M.R.; Adlii, A.; Bakry, B.M. Green fabrication of bentonite/chitosan@cobalt oxide composite (BE/CH@Co) of enhanced adsorption and advanced oxidation removal of Congo red dye and $\mathrm{Cr}(\mathrm{VI})$ from water. Int. J. Boil. Macromol. 2019, 126, 402-413. [CrossRef] [PubMed]

45. Lou, T.; Yan, X.; Wang, X. Chitosan coated polyacrylonitrile nanofibrous mat for dye adsorption. Int. J. Boil. Macromol. 2019, 135, 919-925. [CrossRef] [PubMed]

46. Ahmad, R.; Kumar, R. Adsorption studies of hazardous malachite green onto treated ginger waste. J. Environ. Manag. 2010, 91, 1032-1038. [CrossRef] [PubMed] 
47. Vlysidis, A.; Binns, M.; Webb, C.; Theodoropoulos, C. A techno-economic analysis of biodiesel biorefineries: Assessment of integrated designs for the co-production of fuels and chemicals. Energy 2011, 36, 4671-4683. [CrossRef]

48. Han, W.; Yan, Y.; Gu, J.; Shi, Y.; Tang, J.; Li, Y. Techno-economic analysis of a novel bioprocess combining solid state fermentation and dark fermentation for $\mathrm{H} 2$ production from food waste. Int. J. Hydrogen Energy 2016, 41, 22619-22625. [CrossRef]

49. Ljunggren, M.; Zacchi, G. Techno-economic evaluation of a two-step biological process for hydrogen production. Biotechnol. Prog. 2009, 26, 496-504. [CrossRef]

50. Yunus, Z.M.; Al-Gheethi, A.; Othman, N.; Hamdan, R.; Ruslan, N.N. Removal of heavy metals from mining effluents in tile and electroplating industries using honeydew peel activated carbon: A microstructure and techno-economic analysis. J. Clean. Prod. 2020, 251, 119738. [CrossRef]

Publisher's Note: MDPI stays neutral with regard to jurisdictional claims in published maps and institutional affiliations.

(C) 2020 by the authors. Licensee MDPI, Basel, Switzerland. This article is an open access article distributed under the terms and conditions of the Creative Commons Attribution (CC BY) license (http://creativecommons.org/licenses/by/4.0/). 